\title{
1 Title: Targeting fibrosis in the Duchenne Muscular Dystrophy mice model: an uphill battle
}

2 Marine Theret ${ }^{1 \#}$, Marcela Low ${ }^{1 \#}$, Lucas Rempel ${ }^{1}$, Fang Fang Li $^{1}$, Lin Wei Tung ${ }^{1}$, Osvaldo

3 Contreras $^{3,4}$, Chih-Kai Chang ${ }^{1}$, Andrew Wu ${ }^{1}$, Hesham Soliman ${ }^{1,2}$, Fabio M.V. Rossi ${ }^{1}$

$4{ }^{1}$ School of Biomedical Engineering and the Biomedical Research Centre, Department of Medical 5 Genetics, 2222 Health Sciences Mall, Vancouver, BC, V6T 1Z3, Canada

6 2Department of Pharmacology and Toxicology, Faculty of Pharmaceutical Sciences, Minia 7 University, Minia, Egypt

$8{ }^{3}$ Developmental and Stem Cell Biology Division, Victor Chang Cardiac Research Institute, 9 Darlinghurst, NSW, 2010, Australia

$10{ }^{4}$ Departamento de Biología Celular y Molecular and Center for Aging and Regeneration (CARE-

11 ChileUC), Facultad de Ciencias Biológicas, Pontificia Universidad Católica de Chile, 8331150

12 Santiago, Chile

13 \# Denotes Co-first authorship

15 Keywords: drug screening, fibro/adipogenic progenitors, fibrosis, repair, skeletal muscle.

16 Correspondence to:

17 Marine Theret

18 School of Biomedical Engineering and the Biomedical Research Centre

19 University of British Columbia

202222 Health Sciences Mall, Vancouver, British Columbia

21 Tel: +1(604) 8220441 fax: +1(604) 8227815

22 Email: mtheret@,brc.ubc.ca 


\section{Abstract}

24 Aim: Fibrosis is the most common complication from chronic diseases, and yet no therapy capable

25 of mitigating its effects is available. Our goal is to unveil specific signallings regulating the

26 fibrogenic process and to identify potential small molecule candidates that block fibrogenic

27 differentiation of fibro/adipogenic progenitors.

28 Method: We performed a large-scale drug screen using muscle-resident fibro/adipogenic

29 progenitors from a mouse model expressing EGFP under the Collagen lal promotor. We first

30 confirmed that the EGFP was expressed in response to TGF $\beta 1$ stimulation in vitro. Then we treated

31 cells with TGF $\beta 1$ alone or with drugs from two libraries of known compounds. The drugs ability

32 to block the fibrogenic differentiation was quantified by imaging and flow cytometry. From a two-

33 rounds screening, positive hits were tested in vivo in the mice model for the Duchenne muscular

34 dystrophy (mdx mice). The histopathology of the muscles was assessed with picrosirius red

35 (fibrosis) and laminin staining (myofiber size).

36 Key findings: From the in vitro drug screening, we identified 21 drugs and tested 3 in vivo on the

37 mdx mice. None of the three drugs significantly improved muscle histopathology.

38 Significance: The in vitro drug screen identified various efficient compounds, none of them

39 strongly inhibited fibrosis in skeletal muscle of $\mathrm{mdx}$ mice. To explain these observations, we

40 hypothesize that in Duchenne Muscular Dystrophy, in which fibrosis is a secondary event due to

41 chronic degeneration and inflammation, the drugs tested could have adverse effect on regeneration

42 or inflammation, balancing off any positive effects and leading to the absence of significant results.

\section{Introduction}

44 Acute tissue injury generates transient inflammation and extracellular matrix (ECM) deposition 
45 which return to basal levels after the regenerative process is complete. However, under certain

46 pathologic conditions, persistent damage and inflammation within the tissue generates excessive

47 and chronic deposition of ECM components. This condition of persistent inflammation and

48 elevated ECM is known as fibrosis [1,2]. Fibrosis hinder tissue regeneration and contributes to

49 organ malfunction in different pathologies such as liver and kidney diseases, idiopathic pulmonary

50 fibrosis, heart failure, and muscular dystrophies. Although fibrosis contributes to $45 \%$ of mortality

51 in developed countries, the mechanisms regulating the initiation and the establishment of fibrosis

52 have not yet been completely elucidated[3,4]. Despite the extensive study of fibrogenesis in

53 response to injury, essentially no effective anti-fibrotic therapy is yet available. A better

54 understanding of the cellular effectors and the molecular signals regulating this pathological

55 condition is necessary.

56 In skeletal muscle, an organ with a high regeneration potential, fibrosis is a hallmark of severe

57 muscular dystrophies. This is the case of the incurable Duchenne muscular dystrophy (DMD),

58 where the lack of dystrophin protein leads to cycles of impaired regeneration, resulting in chronic

59 degeneration of the tissue [5-7]. At the cellular level, fibroblasts are the master mediators of tissue

60 fibrosis[8]. In the past 10 years, a group of tissue-resident multipotent mesenchymal progenitors

61 have been described as precursors of fibroblasts. In adult muscles, these cells were named

62 fibro/adipogenic progenitors (FAPs), based on their spontaneous potential to differentiate into

63 myofibroblasts and adipocytes, both in vivo and in vitro [9-11]. Damage induces FAP activation

64 and expansion, which are modulated by inflammatory signals, including Interleukin-4 and 13 (IL-

65 4, IL-13), Tumor Necrosis Factor $\alpha(\mathrm{TNF} \alpha)$, and Transforming Growth Factor $\beta$ (TGF $\beta)[9,12-$

66 17]. Following acute damage, activated FAPs provide trophic support to satellite cells, required

67 for efficient normal regeneration[18-21]. However, in degenerative condition such as in 
68 chronically damaged muscles of DMD patients, tissue clearance of FAPs fails. Chronic damage

69 primes FAPs to differentiate towards both adipocytes and fibroblasts, leading to fibrofatty

70 infiltration, and eventually loss of muscle function[15,22,23]. Due to their dual role in skeletal

71 muscle regeneration/degeneration, FAPs are an ideal cellular target to improve regeneration and

72 prevent fibrofatty deposition[19]. Thus, interventions targeting molecular pathways involved in

73 FAP activation and differentiation are an attractive strategy to combat fibrotic diseases

74 successfully.

75 Inhibition of the TGF $\beta$ signaling pathway during skeletal muscle regeneration reduces FAP 76 number and down-regulates fibrillar collagen type 1 deposition, a hallmark of fibrosis $77[10,15,24,25]$. TGF $\beta$ plays an essential role in tissue modeling and remodeling, and therefore, it is considered a master molecule in the initiation and establishment of fibrosis[26]. The canonical

79 TGF $\beta$ pathway classically transmits extracellular signals via transmembrane serine/threonine 80 kinase receptors and intracellularly via SMAD2/3/4 proteins. The non-canonical TGF $\beta$ pathways

81 include a variety of intracellular cascades activated by TGF $\beta$, independent of SMAD2/3/4. These

82 include the molecules TGF $\beta$-activated kinase 1 (TAK1), mitogen-activated protein kinase

83 (MAPK) such as P38, extracellular signal-regulated kinases (ERK), and JUN N-terminal kinase

84 (JNK), as well as nuclear factor kappa-light chain enhancer of activated B cell (NFkB), among

85 others $[27,28]$. Therapeutic manipulation of the canonical and non-canonical TGF $\beta$ pathways have

86 been shown to be beneficial in multiple myopathic states and fibrosis of various tissues[29].

87 Here, we used the Collagen1a1*3.6 EGFP mice to isolate and culture FAPs and analyze their 88 differentiation into collagen producing cells, by following the expression of the EGFP 89 reporter[30]. We performed a drug screening on freshly isolated FAPs, which allowed us to 90 investigate the role of critical signalling pathways in regulating their fibrogenic differentiation. 
91 Mdx mice (mouse model for the DMD) were treated with compounds that were found to strongly

92 inhibit Collagen expression in vitro. However, none of the drugs reduced fibrosis in vivo. Here,

93 we report that using an in vitro drug screening approach is a feasible technique to delineate

94 pathways leading to the activation of a fibrogenic program. However, in the context of the DMD

95 fibrosis cannot be specifically targeted independently of the other disease components:

96 inflammation and muscle regeneration.

97 Results

\section{Collagen1a1*3.6 EGFP transgenic mice is a reliable and powerful tool for analyzing collagen} expression induced by TGF $\beta 1$

100 We implemented an in vitro model to test compounds for the ability to block or interfere with FAP

101 differentiation along the fibrogenic lineage. Knowing that increased collagen type 1 expression

102 and deposition is a major hallmark of fibrosis [31], we took advantage of the Collagen 1 a $1 * 3.6$

103 EGFP transgenic mouse[30]. These mice express the EGFP gene under the control of a $3.6 \mathrm{~kb}$

104 fragment of rat procollagen type 1 alpha 1 (Collal) regulatory sequences (upstream promoter 105 sequence). The use of this model enables the direct identification of any cell type that actively 106 expresses high levels of Collal type 1 based on EGFP fluorescence.

107 To establish a suitable model capable of tracking FAP differentiation in vitro, EGFP negative FAPs

108 were isolated from Tibialis Anterior (TA) of the Collagen1a1-3.6*EGFP mice 3 days after NTX

109 damage and placed in culture[15,32]. Once they reached $60 \%$ confluency, FAPs were treated with

110 1ng. $\mathrm{ml}^{-1}$ of TGF $\beta 1$ for $72 \mathrm{hr}$, and the percentage of EGFP positive cells was quantified using flow

111 cytometry (Figure 1A). As suggested by previous studies[15], the physiological concentration of

112 1ng. $\mathrm{ml}^{-1}$ was sufficient to increase EGFP expression by $350 \%$ (Figure 1B and C) 
113 These results confirm that FAPs from the Collagen1a1*3.6 EGFP transgenic mice can be used as

114 a robust in vitro model for screening potential blockers of Collal expression.

\section{2. Drug screening in FAPs reveals potential targets for muscle fibrosis therapy}

116 To evaluate the specific molecular pathways regulating FAP fibrogenic differentiation, we

117 performed a drug screening using the in vitro model previously described and validated (Figure

118 1). To do so, EGFP negative FAPs were sorted from TAs and treated with 1 ng.ml ${ }^{-1}$ of TGF $\beta 1$

119 alone or with a set of 722 compounds organized into two libraries, a tyrosine kinase inhibitor

120 library (KIL, 481 compounds) and a TOOL compound library (TOOL, 241 compounds) (Figure

121 S1A, Table 1, and Table 2). Then, the percentage of EGFP positive cells was quantified by using

122 a Cellomics Array scan (Figure S1A). Non-toxic compounds (see methods) with the ability to

123 reduce the expression TGF $\beta 1$-induced EGFP expression by $50 \%$ and with a $p$-value $<0.05$ were

124 selected as positive hits (Tables 1 and 2 Figure 2A, B and S1A). Although 141 compounds met all

125 the selection criteria, only 60 were selected for further assessment as these were compounds

126 available in the market or in advanced phases of clinical development (Tables 1 and 2). For the

127 second round of screening, EGFP negative FAPs were treated as previously described with the

128 selected compounds, and the percentage EGFP positive cells was quantified by flow cytometry

129 (Figure S1A). Figures 2C and 2E show the 21 most potent hits of both libraries that were then

130 further tested in dose-response experiments. A total of 21 compounds showed a dose-dependent

131 decrease in the percentage of EGFP positive cells induced by TGF $\beta 1(p<0.05$, Figure $2 \mathrm{C}$ and $\mathrm{E}$,

132 Table 3). In the KIL library, MAPK inhibitors (VX702 and VX745), tyrosine kinase inhibitors

133 (TyrK) (Nilotinib and Sorafenib), and the Farnesyltransferase inhibitor Tipifarnib significantly

134 reduced the percentage of EGFP positive cells ( $\mathrm{p}<0.05$ or below, Figure $2 \mathrm{C}$ ). In the TOOL library,

135 the Bromodomain inhibitor (BRDI) I-BET151, the histone deacetylase (HDAC) inhibitor PCI- 
13624781 and the PKC activator Indolactam V produced statistically significant reductions in EGFP

137 positive cells $(\mathrm{p}<0.05$ or below, Figure $2 \mathrm{E})$. The most potent hits, with a translational potential

138 from both libraries, were further tested at different doses and dose-response relationships were

139 established (0.1-5 $\mu \mathrm{M})$ (Figure 2D and F). These results show that targets of the TyrK inhibitor

140 and the BRDI families regulate the establishment or maintenance of collagen expression and

141 therefore could be investigated as potential therapies for fibrotic diseases.

142 Interestingly, epigenetic modulators such as the BRDI I-BET151, and the HDAC inhibitor PCI-

143 24781, were among the strongest inhibitors of Collal induction in our screen (as evidenced by

144 EGFP expression)[33]. Based on these results, we tested a drug library composed of epigenetic

145 regulators was tested by following the same procedure described above (Figure S1A). Among 26

146 epigenetic regulators (Table 4), the only group of compounds able to reduce the fluorescence

147 induced by TGF $\beta 1$ were the members of the BRDI family: JQ1, and PFI-1 (Figure 2G). As already

148 demonstrated in the heart, we confirm that the BRDI family members are essential regulators of

149 FAP differentiation into fibroblasts [34]

150 Several transcriptional modifiers and regulators have been described as final effectors of the TGF $\beta$

151 signaling as well as mediating its involvement in fibroblast activation and scar deposition. These

152 include serum responsive factor (SRF)[35], C-ets-1 (ETS1)[36], and NFkB[37]. NFkB pathway

153 modulation has been associated with improvement in muscle health in mdx mice[38-40]. These

154 results suggest that $\mathrm{NF \kappa B}$ might be modulating FAP fibrogenic differentiation and warranted

155 further screening for non-toxic NFkB inhibitors such as Withaferin[41]. Thus, we tested the ability

156 of this compound to reduce collagen expression in vitro by using our previously described method

157 (Figure S1A). Withaferin (WWA) and two of its synthetic analogues (M4 and M27) reduced the

158 percentage of EGFP positive FAPs in vitro at a $0.5 \mu \mathrm{M}$ dose (respectively $-87 \%,-88 \%$, and $-90 \%$, 
$159 \mathrm{p}<0.05)($ Figure $2 \mathrm{H})$. Overall, these results suggest that FAP differentiation into collagen-

160 producing cells can be regulated by multiple signaling pathways, some of which could be

161 independent of the canonical TGF $\beta$ signaling pathway. These results add layers of complexity and

162 suggest that compensatory pathways could influence the results while testing drugs in vivo.

163 3. Non-canonical TGF $\beta$ pathway regulates FAPs fibrogenic differentiation.

164 To validate that the candidate drugs act by another signaling than inhibiting the TGF $\beta$ pathway,

165 we measured the level of activation of the downstream protein p38 MAPK (p-p38) in C3H10T1/2

166 mesenchymal progenitor cells (Figure 3A and B). As previously described[12,15], the treatment

167 with TGF $\beta 1$ increased the phosphorylation levels of p38 by 2.48 -fold. Interestingly, while

168 Nilotinib and Sorafenib are known as TyrK inhibitors, co-treatment of C3H10T1/2 cells with

169 TGF $\beta 1$ and these inhibitors blocked p38 phosphorylation, suggesting that their action works

170 through the p38 MAPK signaling pathway (Figure 3B, respectively $-56 \%$ and $-59 \%$ ). On the other

171 hand, Masitinib, another well-known TyrK inhibitor (targeting Stem Cell Factor (SCF), c-Kit or

172 PDGFR $\alpha$ ) did not reduce p38 phosphorylation in our system. One of the possibilities is that the

173 dose used in this assay was too low to induce any effect, as a decrease in EGFP positive FAP is

174 noticeable only at $5 \mu \mathrm{M}$ for Masitinib (Figure S2). Lastly, while knocking-out BRD4 or using JQ1

175 in vitro on LPS-stimulated microglia is known to induce dephosphorylation of p38[42], TGF $\beta$ -

176 induced p38 MAPK phosphorylation was not affected by JQ1 in our system (Figure 3A and B).

177 In the context of fibrosis, the importance of the SMAD-independent TGF $\beta$ signaling pathway has

178 been highlighted in various fibrosis models and the involvement of TAK1, a common upstream

179 component of this pathway, as a key regulator of fibrosis has been shown in several tissues

180 including kidney[43], skin[44], liver[45], and heart[46,47]. In muscle, TAK1 has been implicated 
181 in the regulation of MuSC fate and myofiber maintenance[48-50]. Moreover, TAK1 is a known 182 activator of the p38 MAPK pathway[51-53], and indeed, the use of a pharmacological inhibitor 183 (5Z-7-Oxozeaenol) decreased TGF $\beta 1$-induced phosphorylation of p38 MAPK $(\mathrm{p}<0.01$; Figure 3A

184 and B). To evaluate the participation of TAK1 in FAP differentiation towards fibroblasts, we 185 evaluated the expression of fibrogenic genes by muscle FAPs in vitro. Sorted FAPs were treated 186 with TGF $\beta 1\left(1 \mathrm{ng} \cdot \mathrm{ml}^{-1}\right)$ with or without 5z-7-Oxozeaenol $(1 \mu \mathrm{M})$ for 6 hours (Figure 3C). In 187 accordance with our previous results, the increase in gene expression of Collagen 1a1 (Colla1), 188 connective tissue growth factor $(C T G F)$, periostin (Postn), Smooth muscle actin (Acta2), and 189 fibronectin $(F n 1)$ induced by TGF $\beta 1$ was attenuated in FAPs incubated with the TAK1 inhibitor 190 5Z-7-Oxozeaenol $(\mathrm{p}<0.05$ or bellow, Figure 3C).

191 Taken together, these results suggest that non-canonical TGF $\beta$ signaling pathways participate in 192 regulating the fibrogenic differentiation of FAPs. Also, we established that central components of 193 this pathways such as TAK1 are playing an important role in modulating FAP fate, which may 194 have significant translational potential for future clinical use.

\section{Testing anti-fibrotic drugs candidates in vivo}

196 To further validate in vivo our in vitro screening results, mdx mice (a murine model for DMD)

197 were fed with a diet containing JQ1 from 4-5-weeks of age for one year (Figure 4A). Overall, the

198 growth rate of treated animals was similar to that of untreated controls, suggesting the absence of 199 systemic toxicity (Figure S3A). However, we noticed that mice fed with JQ1 display muscle mass 200 loss specifically in the Quadriceps $(-18 \%, \mathrm{p}<0.09$; Figure S3B). While collagen deposition 201 (Picrosirius Red coloration (PSR)) in the diaphragm was not affected by the JQ1 diet, the size of 202 myofibers was strongly decreased $(-23 \%, \mathrm{p}<0.05$, Figure 4B to F). JQ1 has previously been 203 demonstrated to have antifibrotic activity in the heart in both aortic constriction and post- 
myocardial infarction settings [34,54], as well as in bleomycin-injured lungs [55]. A possible reason for the discrepancy in the results we obtained from skeletal muscle is that while the studies describing the effect of JQ1 in the heart involved acute injury models, the model we used in this study is a chronic fibrotic disease with a strong inflammatory component. One alternative possibility is that our experimental animal models may not be representative of the clinical picture in patients with fibrosis. The mdx mouse is the most widely used murine model of DMD; however, it does not entirely recapitulate the fibro-fatty progression observed in humans. Indeed, mdx mice

211 develop less fibrosis and with a later onset compared to human patients. In addition, in the murine 212 model the fibrosis is primarily confined to the diaphragm muscle[56]. Other murine models, such

213 as the mdx:utr ${ }^{+/}$, which also lacks one allele of utrophin, a functional analog of dystrophin, have 214 been proposed as a better alternative [57,58]. Indeed, mdx:utr ${ }^{+/-}$mice mimic the human disease 215 more closely and develop more severe fibrosis earlier after disease onset, including in the limb 216 musculature $[59,60]$. As a result, we took advantage of the mdx:utr ${ }^{+/-}$mouse model to further test

217 the effect of JQ1 on muscle fibrosis. We performed continuous infusion of JQ1 (30mg/kg/day) by 218 implanting mice with subcutaneous osmotic minipumps for 4 weeks (5 to 9-weeks-old, Figure 219 4G). The continuous delivery of JQ1 reduced post-natal growth, with 9-weeks-old mouse weight 220 at decreased by $10 \%$ compared to the control group $(\mathrm{p}<0.05$, Figure $\mathrm{S} 3 \mathrm{C})$. Concomitant to this, 221 muscle mass of both gastrocnemius and quadriceps were reduced (respectively $-11 \% \mathrm{p}<0.01$ and $222-11.3 \% \mathrm{p}<0.001$ ) (Figure S3D). Moreover, while the diaphragm's histopathology was not affected 223 (Figure $4 \mathrm{H}$ to L), collagen deposition of TA and gastrocnemius was decreased by $15 \%$ and $10 \%$ $224(\mathrm{p}<0.5$; Figure S3E to G). However, this was not associated with changes in myofiber size (Figure 225 S3H to J).

226 We then decided to test the TyrK inhibitors Nilotinib and Sorafenib. While we previously 
demonstrated that Nilotinib strongly inhibits fibrosis in the muscle and the heart after acute damage[15,61], Nilotinib administration has been associated with adverse effects such as hyperglycemia, increased LDL and HDL, vascular and cardiovascular toxicity when used in the context of long-term treatment[62]. Very recently, White et al., demonstrated that DMD and Becker muscular dystrophy (BMD) patients displayed plasma lipid abnormalities early in the onset of the disease[63]. In addition, in vitro, Nilotinib inhibits C2C12 myoblast differentiation[64]. Thus, Nilotinib is unlikely to be viable as drug for long-term treatment of DMD patients.

In contrast, Masitinib, which is active on a similar range of substrates, does not demonstrate toxicity when tested in vivo and in vitro[65]. To note, while Masitinib demonstrated great inhibitory activity during our first screening, it did not pass our second screening as it was not able to decrease the percentage of EGFP positive cells at concentrations in the therapeutic range (Figure 2A and S2). Masitinib was injected i.p. every day for two weeks in mdx:utr ${ }^{+/-}$mice at $60 \mathrm{mg} / \mathrm{kg} / \mathrm{day}$

239 (Figure 5A). No differences in mouse weight were noticed, confirming the absence of toxicity

240 (Figure S4A). However, only a slight decrease in total collagen content was detected by PSR in 241 the diaphragm $(-12.8 \%, \mathrm{p}<0.05$; Figure 5B and C, Figure S4B). This was associated with no 242 changes in myofiber size in the diaphragm, while a $16 \%$ decrease was observed in the TA $(\mathrm{p}<0.05$;

243 Figure 5D to F and S4C). Finally, to determine whether the results we observed were influenced 244 by to the route of drug administration, we delivered Masitinib for 8 weeks by osmotic minipump 245 implantation (Figure 5G). However, despite this method, no improvement of fibrosis deposition 246 and muscle histopathology was observed (Figure 5H, I, J and N, Figure S4D to F). Lastly, mice 247 were treated with Sorafenib, another promising TyRK inhibitor similar to nilotinib, by using the osmotic pump delivery method for 8 weeks (Figure 5G). Overall, no differences were noticeable 249 on mouse body weight, muscle mass, collagen deposition and myofiber size (Figure 5H, K, L, M 
and N; Figure S4G to I).

\section{Discussion}

252 There is currently no cure for fibrosis, mainly because this condition is a multifactorial factors and

253 likely multiple molecular pathways are involved in triggering, establishing, and maintaining scar-

254 forming disorders and related pathologies. Therapeutic strategies to reduce fibrosis in different

255 tissues have been attempted with limited success [2]. Most of the information that we know about

256 the fate of FAPs and their contribution to muscle regeneration and repair has been done by using

257 skeletal muscle as a model to study fibrosis [9-12,15,20,21,23,66]. Here, we established a 258 screening system using primary FAP cell culture to: 1) Define the intracellular pathways leading

259 to the activation of a fibrogenic program in response to TGF $\beta 1$; 2) Identify a set of drugs capable

260 of interfering with the fibrogenic differentiation of FAPs, to test their therapeutic potential. We

261 found that compounds such as Nilotinib, Sorafenib, JQ1, I-BET151, and Withaferin were able to

262 decrease the expression of Collagen type 1 induced by TGF $\beta 1$.

263 Using muscle resident FAPs, we first confirmed that TGF $\beta 1$ upregulates the expression of Colla1.

264 (Figure 1A-C). To note, collagen expression might not be representative of the other ECM genes

265 such as CTGF/CCN2 or fibronectin, which actively participate in the installation of

266 fibrosis[67,68]. We showed that the local rise of TGF $\beta$ concentration in skeletal muscle after acute

267 damage pushes FAPs towards fibrogenic differentiation. Similar results have been obtained by

268 others and ourselves, where the expansion of resident FAPs is closely associated with elevated

269 TGF $\beta$ levels and increased ECM deposition during regeneration and repair[22,69,70]. In addition,

270 we previously showed a temporal correlation between the peak of TGF $\beta$ expression in the tissue

271 and the Collal levels after skeletal muscle acute damage at day $7[15,20]$. 
272 For some of the compounds emerging form our screen, an anti-fibrotic effect had previously been

273 demonstrated in different organs, including lung, kidney, liver, heart, and skeletal muscle.

274 Members of the TyrK inhibitor family such as Imatinib[25,71,72], Nilotinib[15,20,73-75],

275 Sorafenib[76], Sunitinib[77]; and epigenetic regulators such as BRD4 and HDAC inhibitors have

276 been effective in blocking fibrosis[55,78-81]. BRD regulators specifically recognize acetylated

277 lysine residues, which act as scaffolds and attract components of the transcriptional machinery to

278 the acetylated lysine residues of histones, resulting in modulation of gene transcription. This

279 finding is particularly interesting because the role(s) of epigenetic regulators in fibrosis and their

280 therapeutic potential is still poorly understood[82]. Pharmacologic modulation of epigenetic

281 readers is emerging as a novel therapeutic approach for the treatment of inflammatory

282 diseases[82].

283 Here, we identify FAPs as pharmacological targets for the action of TyrK, BRD and p38 MAPK

284 inhibitors. The TGF $\beta$-TAK1 pathway is a shared molecular pathway regulating TyrK, BRD and

285 p38 MAPK signaling. Growing evidence supports the role of TAK1 as a significant regulator of

286 TGF $\beta$ signaling through the regulation of the profibrotic response in several systems[43-45,83-

287 87]. Very recently, it has been shown that the action of Catalpol (an anti-inflammatory and

288 antioxidant drug from Chinese medicinal herb Rehmannia) on DMD histopathology was due to its

289 binding to TAK1 $[88,89]$. Besides its role in fibrosis, TAK1 also has been described as an important

290 mediator of carcinogenesis and cell survival[90]. In all these settings, TAK1 regulates inducible

291 transcription factors such as NFkB, and other kinases such as p38 MAPK and c-Jun N terminal

292 kinases (JNKs)[38,51-53,91]. In our initial drug screening, all the TAK1 inhibitors tested were

293 found to be toxic, thus confirming its central role in cell survival. For this reason, we did not pursue

294 the use of the TAK1 inhibitors in vivo. 
295 We also tested a natural compound, Withaferin A, and two chemical derivatives, known for their 296 inhibitory effect on the transcription factor NFkB[92,93]. Using the Colla1-EGFP model 297 presented here, we observed a decrease in EGFP positive cells in Withaferin A treated FAPs, 298 suggesting that the NFkB factor might be playing a role in regulating the expression of collagen 299 in FAPs. Similar results were found in the heart, where Withaferin A reduced type I collagen 300 expression in vitro and inhibited the development of myocardial fibrosis in vivo[94]. Dysregulation 301 of NFkB activity can contribute to chronic inflammatory diseases such as dystrophies. Treatments 302 with NFkB inhibitors improved muscle function in mdx mice[39,40]. The use of Withaferin A has 303 been associated with decreased inflammation in several models[95], and may be due to an effect 304 on early inflammatory stages of fibrosis. However, in our hands, mice treated with Withaferin in 305 i.p (IMS-088). displayed swelling of the abdominal area and peritoneal adhesions, resulting in the 306 interruption of its testing in vivo (data not shown).

307 JQ1 is an inhibitor or the BET family of proteins which includes BRD2, 3 and 4[96]. Its action as 308 an antifibrotic has been demonstrated in various tissues, including the heart, lungs, kidneys, and 309 the liver[34,54,78,97,98]. In this study, we tested the action of JQ1 on muscle fibrosis with long310 term treatment (medicated food for one year) and a short-term treatment (osmotic minipump for 4 311 weeks). While we did detect a small decrease in fibrosis in TA and GC with the short-term 312 treatment, we also detected a substantial decrease in myofiber size in the diaphragm of the mice 313 treated with JQ1 for a year, suggesting that the drug affects fiber maintenance or metabolism

314 (Figure 4 and S3). We speculate that the absence of effect on matrix deposition commensurable 315 with that observed in vitro may be due to an unbalance between the anti-fibrotic and the anti316 inflammatory function of JQ1[99,100]. Lastly, the use of TyrK inhibitors, especially Nilotinib, in 317 vitro and in vivo has shown promising results in various settings and fibrotic 
318 diseases[15,61,76,101,102]. However, Nilotinib has been shown to induce side effects in long-

319 term treated patients[62], and off-target effects in skeletal muscle myogenic progenitors[64].

320 Because of that, and despite the fact that it reduces Colla1-EGFP levels only at higher doses (5

$321 \mu \mathrm{M})$, we focused on the TyrR inhibitor Masitinib as a candidate to replace Nilotinib. Currently,

322 Masitinib is used in 31 clinical trials (NIH clinicalTrials.gov). However, while it also induced a

323 slight decrease in fibrosis content in the diaphragm, it did not improve the overall histopathology

324 of the disease (Figure 5 and S4). Similar results were found with the TyrK inhibitor Sorafenib.

325 One of the many possible explanations would be that the drugs, as does Nilotinib, also interact

326 with immune cells, endothelial cells, and muscle cells (progenitors and myofibers)[64]. Indeed,

327 MAPK p38, NFkB, KIT, PDGF, and FGF signaling pathways regulate immune cell 328 functions[103,104], vascularization[105,106], or myogenic cell proliferation, differentiation, and 329 myofiber growth[107-109].

330 In conclusion, here we show that in a model system in which fibrosis is a secondary event caused

331 by dysfunction of the parenchymal muscle stem cells and fibers, inhibitors capable of preventing

332 the activation of a fibrogenic transcriptional programme seem to be inefficient in protecting against

333 the disease. These results contribute to the growing evidence that modeling fibrotic diseases in 334 vitro to perform drug screening may not yield hits that will perform well in in vivo 335 models[110,111].

\section{Materials and methods}

\section{Animals}

339 Mice were maintained in an enclosed and pathogen-free facility. Mice were housed in standard 
cages under $12 \mathrm{~h}$ light-dark cycles and fed ad libitum with a standard chow diet. All experimental

341 procedures were approved by the University of British Columbia Animal Care Committee.

342 Transgenic mice expressing the enhanced green fluorescent protein (EGFP) under a Collagenla1

343 enhancer, Collal*3.6-eGFP, were a gift from Pr. D.W. Rowe (Center for Regenerative Medicine

344 and Skeletal Development, University of Connecticut Health Center, USA). mdx:utr ${ }^{+/-}$mice were

345 a gift from Dr. Lisa Hoffman (Western University, London, ON, Canada). Adult mice >8-weeks-

346 old, both male and female, were used unless otherwise specified. Acute muscle damage was

347 induced by intramuscular injection of $0.15 \mu \mathrm{g}$ notexin (NTX) snake venom (Latoxan), into the 348 tibialis anterior muscle (TA).

349 Mice were fed with control diet (Research Diet, \#D111112201) or JQ1 diet (control diet 350 supplemented with JQ1 at $25 \mathrm{mg} / \mathrm{kg}$ (Cayman Chemical \#11187, or Selleckchem \#S7110)).

351 Mice were daily treated by intraperitoneal (i.p.) injection with the vehicle (DMSO/ETOH=1:1), or 352 Masitinib (ABSCIENCE, \#AB1010, $60 \mathrm{mg} / \mathrm{kg} /$ day).

\section{Mini osmotic pump}

354 The empty mini osmotic pump (ALZET; model 2002) was filled with the vehicle 355 (DMSO/ETOH=1:1) or drug solution (JQ1: Cayman Chemical \#11187 or Selleckchem \#S711, 30

$356 \mathrm{mg} / \mathrm{kg} /$ day; Masitinib: ABSCIENCE \#AB1010, 60 mg/kg/day; Sorafenib: BAYER \#BXA5X4R,

$3576 \mathrm{mg} / \mathrm{kg} /$ day) in sterile conditions. In order to allow the pump to equilibrate and reach its steady-

358 state pumping rate, the filled pumps were primed overnight in sterile saline at $37^{\circ} \mathrm{C}$. Animal were

359 anesthetized and shaved. A $1 \mathrm{~cm}$ incision was performed on the skin and a pocket was created with

$3601 \mathrm{ml}$ of sterile saline. The osmotic pump was slowly inserted, then the muscle layer was gently

361 tented and closed with 6-0 monocryl. By using an 18G needle, a hole was then poked in the muscle

362 layer. The catheter was fed through the hole until the first retention bead passed through and into 
363 the peritoneal space. To finish, the purse string suture was tightened using square knots. The

364 catheter was allowed to sit naturally by adjusting the pump. Finally, the skin layer was closed using 365 an intradermal pattern.

\section{Histology}

367 Before tissue collection, animals were perfused transcardially with $20 \mathrm{ml}$ of 1 X PBS $4 \%$ PFA.

368 Tissues were processed for paraffin-embedding using standard methods. Sections of muscle tissues 369 were stained with picrosirius red (PSR) in order to quantify collagen deposition.

370 For laminin staining, sections were deparaffinized and antigen retrieval performed in proteinase K 371 buffer (Abcam, \#ab64220) for $20 \mathrm{~min}$ at room temperature (RT). Slides were then washed in 1X 372 PBS and then incubated in a blocking solution containing 3\% normal goat serum and $0.3 \%$ triton

$373 \mathrm{X}-100$ in $1 \mathrm{X}$ PBS for 60 mins at RT prior to incubation with Laminin (Abcam \#ab11575; 1:200)

374 at $4^{\circ} \mathrm{C}$ overnight. Slides were then washed with $1 \mathrm{X}$ PBS and incubated in blocking solution 375 containing the secondary antibodies (ThermoFisher) for 2 hours at RT. Following antibody 376 incubation, $3 \times 5$ min PBS washes were performed, and sections were stained with DAPI for 10 377 min (ThermoFisher, \#D3571, $0.6 \mu \mathrm{M}$ ) before being mounted with fluorescent mounting medium 378 (Dako).

\section{$379 \quad$ Imaging}

380 PSR and laminin images were acquired at 10X magnification using a Nikon Eclipse Ni equipped

381 with a device camera (Nikon Digital Sight DS-U3 for brightfield, Qimaging Retiga EXi for 382 fluorescence) and operated via NIS software. Collagen deposition and CSA were calculated using 383 Fiji (ImageJ, version 2.0.0-rc/69/1.52n, NIH, MD) and Open-CSAM[112]. Images were 384 assembled using Adobe Illustrator CS6 (Adobe) 
FAP were isolated and cultured as described in[32] with some modifications. Hindlimbs or damaged TAs were carefully dissected and gently torn with tissue forceps. Enzymatic digestion was performed with Collagenase D (Roche Biochemicals; $1.5 \mathrm{U} / \mathrm{ml}$ ) and Dispase II (Roche Biochemicals; $2.4 \mathrm{U} / \mathrm{ml}$ ), at $37^{\circ} \mathrm{C}$ for $60 \mathrm{~min}$. Preparations were passed through $70 \mu \mathrm{m}$ and $40 \mu \mathrm{m}$

390 cell strainers (Becton Dickenson), and washed in 1X PBS containing 2 mM EDTA and 2\% FBS

391 (FACS buffer). Resulting single cells were collected by centrifugation at $300 \mathrm{~g}$ for $5 \mathrm{~min}$. Cell 392 homogenate was incubated with primary antibodies for $30 \mathrm{~min}$ at $4^{\circ} \mathrm{C}$ in FACS buffer. Monoclonal 393 primary antibodies were used as following: anti-CD31 (eBioscience, clone: 390), anti-CD45 394 (AbLab, clone: I3/2), anti-Sca-1 (eBioscience, clone: D7) and anti- $\alpha 7$ integrin (AbLab, clone: 395 R2F2). Cells were stained with Hoechst $33342\left(2.5 \mu \mathrm{g} \cdot \mathrm{ml}^{-1}\right.$, Sigma) and resuspended in FACS 396 buffer immediately before sorting. Sorting was performed on FACS Aria II (Becton Dickenson) 397 or Influx (Becton Dickenson). Gates were defined based on fluorescence minus one (FMO) 398 controls and EGFP negative FAPs were sorted as CD31/CD45/a7int- Sca1+ GFP-. For in vitro 399 experiments, FAPs were seeded at a density of $10.000 \mathrm{cell} / \mathrm{cm}^{2}$ in high-glucose Dulbecco's 400 modified eagle medium (DMEM) (Invitrogen) supplemented with 10\% FBS and $1.5 \mathrm{ng} / \mathrm{ml} \beta$-FGF 401 (Invitrogen).

\section{In vitro drug screening}

403 EGFP negative FAPs were plated at 10,000 cells $/ \mathrm{cm}^{2}$ in 384 well-plates (Falcon) and treated at $40450-60 \%$ confluence, either with rh-TGF $\beta 1\left(1\right.$ ng.ml $\left.{ }^{-1}\right)($ eBioscience $)$ or rh-TGF $\beta 1+$ drugs in 405 DMEM 5\% FBS.

406 For the first screening, 6 to 8 mice were pooled before sort and four to nine technical replicates 
were performed. 722 chemical compounds (Table 1 and 2) organized into two libraries (KIL and

408 TOOL, donated by Dr. Rima Al-awar (Ontario Cancer Institute, Toronto) were tested. After a 72h

409 treatment period, cells were fixed with paraformaldehyde (PFA) 4\% for 10 min, and Hoechst

41033342 (Sigma) was used for nuclei staining. Viability and GFP expression were analyzed using

411 Cellomics Array scan (Thermo Fisher Scientific).

412 For the second screening, 6 to 8 mice were pooled before sort, triplicate were performed and the 413 experiment was repeated at least 2 times. screening was performed on 60 compounds in the same 414 condition as previously described at a $1 \mu \mathrm{M}$ dose. After 72 hours, cells were detached from the 415 plate using trypsin and resuspended in FACS buffer and Hoechst 33342 (Sigma). Percentage of 416 EGFP positive cells was calculated on the total event that were Hoechst+. The most significant 417 drugs were finally tested in a dose response $(0.01$ to $5 \mu \mathrm{M})$ and the percentage of FAP EGFP 418 positive was analyzed by FACS.

419 An epigenetic library of 26 compounds was obtained from Chemical Probes and was screened by 420 flow as previously described (concentrations of 0.25 and $1 \mu \mathrm{M}$ ). Withaferin and its derivatives 421 compounds (Imstar Therapeutics) were tested at a range of 0.06 to $0.5 \mu \mathrm{M}$ concentrations. 422 Percentage of EGFP positive FAPs was quantified by flow cytometry as described above.

423 Lastly, once FAP reached 60\% confluence, the cells were incubated in 5\% FBS, no bFGF prior to 424 being stimulated with $\operatorname{rf}-\mathrm{TGF} \beta 1\left(1 \mathrm{ng} \cdot \mathrm{ml}^{-1}\right)$ and later with or without 5-z-7Oxozeanol at $1 \mathrm{nM}$ for 4256 hours. RNA isolation was performed using RNAzol reagents as per the supplier's instructions.

\section{$426 \quad R T-P C R$ and $d d P C R$}

427 Reverse transcription was performed using 100 ng of RNA and Superscript Reverse Transcriptase 428 according to the supplier's instructions (Applied Biosystems). The cDNA was diluted ten times in 
RNAse free water (Thermofisher) and $2.5 \mu 1$ was used in a reaction mix containing Droplet Digital PCR Supermix (Bio-Rad), TaqMan assay and RNAse free water. The Taqman probes (Suppl Table

431 1) used were the following: droplets were generated with a QX100 droplet generator (Bio-Rad), 432 after mixing $20 \mu \mathrm{l}$ of reaction mix and $70 \mu \mathrm{l}$ of droplet generator oil (Bio-Rad). The emulsified 433 samples were loaded onto 96-well plates and endpoint PCRs were performed in C1000 Touch 434 thermal cycler (Bio-Rad) at the following cycling conditions: $95{ }^{\circ} \mathrm{C}$ for $10 \mathrm{~min}$, followed by 45 cycles at $94{ }^{\circ} \mathrm{C}$ for $30 \mathrm{~s}$ and $60^{\circ} \mathrm{C}$ for $1 \mathrm{~min}$, followed by $98{ }^{\circ} \mathrm{C}$ for $10 \mathrm{~min}$. The droplets from

436 each sample were read through the QX200 droplet reader (Bio-Rad). Resulting PCR-positive and 437 PCR-negative droplets were counted using QuantaSoft software (Bio-Rad). Data for each gene 438 were normalized to hprt expression.

\section{9}

440

\section{1}

\section{Cell culture}

C3H10T1/2 is a cell line of mesenchymal progenitors (Clone 8, American Type Culture Collection, Manassas, USA), the cells need to be maintained at 50-70\% confluence. C3H10T1/2 cells were grown at $37{ }^{\circ} \mathrm{C}$ in $5 \% \mathrm{CO} 2$ in growth medium; high-glucose Dulbecco's modified Eagle's medium (DMEM) (Invitrogen), supplemented with 10\% fetal bovine serum (FBS) and Penicillin/streptomycin. For western blot analysis, cells were serum-starved for $1 \mathrm{hr}$ before being treated with rh-TGF $\beta-1$ (e-Bioscience) in DMEM supplemented with $2 \%(\mathrm{v} / \mathrm{v}) \mathrm{FBS}$. Specific treatments the following inhibitors were also used at $1 \mu \mathrm{M}$ final concentration: Nilotinib (Tasigna ${ }^{\circledR}$, AMN107; Novartis), Sorafenib (Bayer), JQ-1 (Cayman Chemical), 5Z-7-Oxozeaenol (Cayman Chemical). Protein extracts were done after 30 min of incubation at $37^{\circ} \mathrm{C}$ in $5 \% \mathrm{CO} 2$.

\section{Protein extraction and western blot}

Protein extracts from cells were obtained using RIPA 1X lysis buffer (\#9806 Cell signaling, MA, USA) plus protease/phosphatase inhibitors (\#P8340 and \#P0044, Sigma-Aldrich, USA). Cells 
452 were sonicated for $10 \mathrm{~s}$ and centrifuged at $9000 \mathrm{~g}$. Proteins were quantified with the Micro BCA

453 assay kit following the manufacturer's instructions (Pierce, IL, USA). Extracts were subjected to

454 SDS-PAGE electrophoresis in 9\% polyacrylamide gels, transferred to PDVF membranes

455 (Millipore, CA, USA), and probed with primary antibodies: rabbit anti-phospho-p38

456 (Thr180/Tyr182) (\#9211S, Cell Signaling, USA), rabbit anti-p38 (\#9212, Cell Signaling, USA)

457 and mouse anti- $\beta$-actin (\#21001901, AbLab, BC, CA). Then, primary antibodies were detected

458 with IRDye ${ }^{\circledR}$ Infrared Dye labeled secondary antibodies (LI-COR). All immunoreactions were

459 visualized by with an Odyssey ${ }^{\circledR}$ imaging system. Western blot densitometry quantification was

460 done using Fiji (ImageJ) software. Protein levels were normalized with the levels of the loading

461 control.

\section{Statistical analysis}

463 Graph and statistical tests were performed using Prism 8 (GraphPad Software, La Jolla California, 464 USA). Depending on the experiment, one-way or two-way ANOVA were performed, corrections

465 were applied, followed by post-hoc test. Gaussian distribution was not assumed. A probability of $466<5 \%(\mathrm{p}<0.05)$ was considered statistically significant. Sample size and/or technical replicate 467 number for each experiment is indicated in the figure legend. Graphs are represented as mean \pm 468 standard error of the mean. Figures were assembled using Adobe Illustrator CS6 (Adobe) 
473 (A) Collagen1a1*3.6 EGFP mice were injected with notexin (NTX) in the tibialis anterior (TA)

474 muscle at day 0 (D0). 3 days post injury, Collagen-EGFP negative FAPs were cell sorted and

475 plated before been treated with $1 \mathrm{ng} / \mathrm{ml}$ of TGF $\beta 1$ for 72 hours (B-C). GFP expression was

476 analyzed by flow cytometry as a measure of Collagen gene expression. $n=3$ biological replicates.

477 Treatment versus NT: $\mathrm{p}<0.01, * * *$

$478 \quad$ Figure 2: Drug screening targeting Collagen type I expression

479 (A-B) Tibialis anterior (TA) muscles of Collagen1a1*3.6 EGFP mice were injected with notexin 480 (NTX). Three days after injury, EGFP negative FAPs were cell sorted and treated with TGF $\beta 1$

481 alone or with compounds from the KIL and TOOL libraries. Collagen-GFP expression was 482 quantified using a Cellomic Arrayscan (Figure S1). 4 to 9 experimental replicates were performed

483 (C) Sorted EGFP negative FAPs were treated with TGF $\beta 1$ and with selected compounds from the

484 first round of screening of the KIL library. Percentage of EGFP positive cells was quantified by 485 flow cytometry. Each technical replicate is presented performed (5 to 14 )

486 (D) Selected positive hits from the KIL library (Sorafenib, Nilotinib and Tipifarnib) were then 487 tested as described at concentrations ranging from 0.5 to $5 \mu \mathrm{M}$. 2 biological replicates were 488 performed.

489 (E) Sorted EGFP negative FAPs were treated with TGF $\beta 1$ and with selected compounds from the 490 first round of screening of the TOOL library. GFP expression was quantified using flow cytometry. 491 Each technical replicate is presented performed (3 to 10)

492 (F) Selected compounds from the TOOL library (Indolactam V, I-BET 151 and PCI-24782) were 493 then tested in a dose dependent manner from 0.5 to $1 \mu \mathrm{M}$. 2 to 4 biological replicates were 494 performed 
495 (G) Compounds from the "epiprobe" library were tested at 0.25 and $1 \mu \mathrm{M}$. Collagen-GFP 496 expression was quantified using flow cytometry. 3 biological replicates were performed

497 Drug versus TGF $\beta 1: *: \mathrm{p}<0.05, * *: \mathrm{p}<0.01$

$498 \quad$ Figure 3: TAK1-p38 axis regulates FAP differentiation into fibroblasts

499 (A-B) C3H10T1/2 cell line was stimulated for $30 \mathrm{~min}$ with $\mathrm{rh}-\mathrm{TGF} \beta 1(1 \mathrm{ng} / \mathrm{ml})$ alone or with 1

$500 \mu \mathrm{M}$ of Nilotinib, Sorafenib, Masitinib, JQ-1, or (5Z)-7-Oxozeanol. Protein lysates were extracted 501 and Western Blot for p38, phospho-p38, phospho-TAK1 and $\beta$-Actin performed, and the data 502 quantified. $n=4$.

503 (C) EGFP negative FAPs were treated for 6 hours with $1 \mathrm{ng} / \mathrm{ml}$ of $\mathrm{rh}-\mathrm{TGF} \beta 1$ with or without 1 $504 \mathrm{uM}$ of (5Z)-7-Oxozeanol. Gene expression of Colla1, Acta2, CTGF, Fn1, and Postn was 505 quantified by digital droplet PCR and normalized to the expression of hprt. $\mathrm{n}=3$.

506 Treatment + rh-TGF $\beta 1$ versus rh-TGF $\beta 1:^{*}: \mathrm{p}<0.05 ; * *: \mathrm{p}<0.01$

\section{Figure 4: Treatment of JQ1 worsens DMD pathology}

508 (A-F) mdx mice were fed with a control or a JQ1-medicated diet (30 mg/kg/day) for up to a year.

509 Diaphragm collagen deposition (B-C) and myofiber size (D-F) were quantified. $n=4$

510 (G-L) mdx:utr ${ }^{+/-}$mice were implanted with an Alzet osmotic pumps containing JQ1 or its vehicle 511 for 4 weeks. Diaphragm collagen deposition (H-I) and myofiber size (J-L) were quantified. $\mathrm{n}=10$

512 to 12

513 JQ1 versus control: * $\mathrm{p}<0.05 ; * * \mathrm{p}<0.01 ; * * * \mathrm{p}<0.001$

$514 \quad$ Scale bar $=100 \mu \mathrm{m}$

515 Figure 5: Sorafenib and Masitinib treatments do not improve DMD histopathology 
516 (A-F) mdx:utr ${ }^{+/-}$mice were injected i.p. with $60 \mathrm{mg} /$ day $/ \mathrm{kg}$ of Masitinib from 8 to 11 -weeks-old.

517 Diaphragm collagen deposition (B-C) and myofiber size (D-F) were quantified. $\mathrm{n}=6$ to 8

518 (G-O) mdx:utr ${ }^{+/-}$mice were implanted with osmotic pumps containing either Masitinib, Sorafenib

519 or the appropriate control vehicle from 5 to 14-weeks-old. Diaphragm collagen deposition $(\mathbf{H}, \mathbf{L}$,

$520 \mathbf{K}, \mathbf{O})$ and myofiber size $(\mathbf{I}, \mathbf{J}, \mathbf{M}, \mathbf{N})$ were quantified. $\mathrm{n}=4$

521 Treated mice versus control: *:p $<0.05$,

522 Scale bar $=100 \mathrm{um}$

$523 \quad$ Figure S1: In vitro drug screening scheme.

$524 \quad 1^{\text {st }}$ screening:

525 Tibialis anterior (TA) muscles of Collagen1a1*3.6 EGFP mice were injected with notexin (NTX).

526 Three days after injury, EGFP negative FAPs were sorted, plated in 384 well-plates and treated at $52750-60 \%$ confluence, either with recombinant human TGF $\beta\left(1 \mathrm{ng} \cdot \mathrm{ml}^{-1}\right)(\mathrm{eBioscience})$ or TGF $\beta 1+$ 528 drug. After 72 hours of treatment, cells were fixed and stained for nuclei detection. Viability and 529 GFP expression were analyzed using Cellomics Array scan (Thermo Fisher Scientific).

$530 \quad 2^{\text {nd }}$ screening:

531 EGFP negative FAPs were sorted from NTX-injected TAs, plated in 48 well-plates and treated 532 when reached 50-60\% confluence, either with rh-TGF $\beta\left(1\right.$ ng.ml $\left.{ }^{-1}\right)$ (eBioscience) or rh-TGF $\beta 1+$ 533 drug. After 72 hours, cells were detached from the plate using trypsin, resuspended in FACS buffer 534 and stained with Hoechst 33342. Percentage of EGFP positive cells was calculated based on the 535 total Hoechst+ events.

$536 \quad$ Figure S2: Masitinib inhibits Collagen-EGFP expression induced by TGF $\beta 1$ 
537 Tibialis anterior (TA) muscles of Collagen1a1*3.6 EGFP mice were injected with notexin (NTX).

538 Three days after injury, EGFP negative FAPs were cell sorted and plated before been treated with

539 rh-TGF $\beta 1$ alone or with Masitinib as different doses $(0.01$ to $5 \mu \mathrm{M} . \mathrm{n}=1$ to 2$)$

$540 \quad$ Figure S3: In vivo validation of JQ1

541 (A-B) mdx mice were fed with control diet or JQ1 diet (30 mg/kg/day) for up to a year. Mouse

542 mass (A) and muscle mass (B) were measured. $\mathrm{n}=4$

543 (C-J) mdx:utr ${ }^{+-}$mice were implanted with pumps containing JQ1 or its vehicle for 4 weeks.

544 Mouse body mass (C) and muscle mass (D) were measured. TA, GC, and Quad collagen deposition

545 (E-G), as well as myofiber size $(\mathbf{H}-\mathbf{J})$ were quantified. $\mathrm{n}=10$ to 12

546 End-point versus starting point: $\$ \$ \$ p<0.001$

547 JQ1 versus control: ${ }^{*} \mathrm{p}<0.05 ; * * \mathrm{p}<0.01 ; * * * \mathrm{p}<0.001$

$548 \quad$ Figure S4: In vivo validation of Masitinib and Sorafenib

549 (A-C) mdx:utr ${ }^{+/-}$mice were injected in i.p. with Masitinib or its vehicle from 8 to 11-weeks-old.

550 Mouse body mass was measured (A). TA, GC, and Quad collagen deposition (B), as well as

551 myofiber size $(\mathbf{C})$ were quantified. $n=6$ to 8

552 (D-F) mdx:utr ${ }^{+/-}$mice were implanted with minipumps containing Masitinib or its vehicle for 9

553 weeks. Mouse body mass was measured (D). TA and GC collagen deposition (E), as well as

554 myofiber size $(\mathbf{F})$ were quantified. $\mathrm{n}=4$

555 (G-I) $\mathrm{mdx}: \mathrm{utr}^{+/-}$mice were implanted with minipumps containing Sorafenib or its vehicle for 9

556 weeks. Mouse body mass was measured (G). TA and GC collagen deposition (H), as well as

557 myofiber size (I) were quantified. $\mathrm{n}=4$ 
558 End-point versus starting point: $\$ p<0.05 ; \$ \$ \$ p<0.001$

559 Treatment versus control: $* \mathrm{p}<0.05$

561 Acknowledgments

562 The authors would like to thank Professor David W. Rowe (Center for Regenerative Medicine and

563 Skeletal Development, University of Connecticut Health Center, USA) and Doctor Lisa Hoffman

564 (Western University, London, ON, Canada) for gifting us the Colla1*3.6-eGFP and the mdx:utr+/-

565 mouse colonies. We would like also to thank Dr. Rima Al-awar (Ontario Cancer Institute, Toronto)

566 for kindly gifting us the TOOL and KIL libraries, as well as Andrew Johnson, Justin Wong (UBC

567 Flow core), and Josh Hashimoto for their help.

568 Author contributions

569 M.T., M.L., C.C., L.R., F.L., O.C., L.W.T., and A.W. were responsible for performing and

570 analyzing experiments. M.T., M.L., H.S., and F.M.V.R. were involved in experimental design,

571 data interpretation, and preparation of the manuscript. All authors were involved in editing the

572 manuscript.

\section{Competing interests}

574 The authors declare no competing or financial interests.

\section{$575 \quad$ Funding}

576 This work was supported by the Fondation pour la Recherche Médicale (FRM; 40248 to M.T.);

577 European Molecular Biology Organization (EMBO; ALTF 115-2016 to M.T.), by the Association

578 contre les myopathies (AFM; 22576 to MT), by Michael Smith Foundation for Health Research 
(MSFHR; 18351 to MT), by the Agencia Nacional de Investigación y Desarrollo (ANID;

16-1-0327).

\section{References}

[1] A.K. Ghosh, S.E. Quaggin, D.E. Vaughan, Molecular basis of organ fibrosis: Potential therapeutic

[2] V.J. Thannickal, C.A. Henke, J.C. Horowitz, P.W. Noble, J. Roman, P.J. Sime, Y. Zhou, R.G. Wells, E.S. White, D.J. Tschumperlin, Matrix biology of idiopathic pulmonary fibrosis: A workshop report of the national heart, lung, and blood institute, Am. J. Pathol. 184 (2014). https://doi.org/10.1016/j.ajpath.2014.02.003.

[3] J. Rosenbloom, F.A. Mendoza, S.A. Jimenez, Strategies for anti-fibrotic therapies, Biochim. Biophys. Acta Mol. Basis Dis. 1832 (2013). https://doi.org/10.1016/j.bbadis.2012.12.007.

[4] N.C. Henderson, F. Rieder, T.A. Wynn, Fibrosis: from mechanisms to medicines, Nature. (2020). https://doi.org/10.1038/s41586-020-2938-9.

[5] Y. Kharraz, J. Guerra, P. Pessina, A.L. Serrano, P. Muñoz-Cánoves, Understanding the process of fibrosis in duchenne muscular dystrophy, Biomed Res. Int. 2014 (2014). https://doi.org/10.1155/2014/965631.

[6] S. Dadgar, Z. Wang, H. Johnston, A. Kesari, K. Nagaraju, Y.W. Chen, D. Ashley Hill, T.A. Partridge, M. https://doi.org/10.1083/jcb.201402079.

[7] A.L. Serrano, P. Muñoz-Cánoves, Fibrosis development in early-onset muscular dystrophies: Mechanisms and translational implications, Semin. Cell Dev. Biol. 64 (2017). https://doi.org/10.1016/j.semcdb.2016.09.013.

[8] B. Hinz, Formation and function of the myofibroblast during tissue repair, J. Invest. Dermatol. 127 (2007). https://doi.org/10.1038/sj.jid.5700613.

[9] A.W.B. Joe, L. Yi, A. Natarajan, F. Le Grand, L. So, J. Wang, M.A. Rudnicki, F.M.V. Rossi, Muscle injury activates resident fibro/adipogenic progenitors that facilitate myogenesis, Nat. Cell Biol. 12 (2010). https://doi.org/10.1038/ncb2015.

[10] A. Uezumi, S.I. Fukada, N. Yamamoto, S. Takeda, K. Tsuchida, Mesenchymal progenitors distinct from satellite cells contribute to ectopic fat cell formation in skeletal muscle, Nat. Cell Biol. 12 (2010). https://doi.org/10.1038/ncb2014.

[11] N. Arrighi, C. Moratal, N. Clément, S. Giorgetti-Peraldi, P. Peraldi, A. Loubat, J.Y. Kurzenne, C. Dani, A. Chopard, C.A. Dechesne, Characterization of adipocytes derived from fibro/adipogenic progenitors resident in human skeletal muscle, Cell Death Dis. 6 (2015). https://doi.org/10.1038/cddis.2015.79.

[12] O. Contreras, M. Cruz-Soca, M. Theret, H. Soliman, L.W. Tung, E. Groppa, F.M. Rossi, E. Brandan, Crosstalk between TGF- $\beta$ and PDGFR $\alpha$ signaling pathways regulates the fate of stromal fibro-adipogenic progenitors, J. Cell Sci. 132 (2019). https://doi.org/10.1242/jcs.232157. 
[14] J.E. Heredia, L. Mukundan, F.M. Chen, A.A. Mueller, R.C. Deo, R.M. Locksley, T.A. Rando, A. Chawla, Type 2 innate signals stimulate fibro/adipogenic progenitors to facilitate muscle regeneration, Cell. 153 (2013). https://doi.org/10.1016/j.cell.2013.02.053.

[15] D.R. Lemos, F. Babaeijandaghi, M. Low, C.K. Chang, S.T. Lee, D. Fiore, R.H. Zhang, A. Natarajan, S.A. Nedospasov, F.M.V. Rossi, Nilotinib reduces muscle fibrosis in chronic muscle injury by promoting TNFmediated apoptosis of fibro/adipogenic progenitors, Nat. Med. 21 (2015). https://doi.org/10.1038/nm.3869.

[16] Y. Dong, K.A.S. Silva, Y. Dong, L. Zhang, Glucocorticoids increase adipocytes in muscle by affecting IL-4 regulated FAP activity, FASEB J. (2014). https://doi.org/10.1096/fj.14-254011.

[17] X. Kang, M.Y. Yang, Y.X. Shi, M.M. Xie, M. Zhu, X.L. Zheng, C.K. Zhang, Z.L. Ge, X.T. Bian, J.T. Lv, Y.J. Wang, B.H. Zhou, K.L. Tang, Interleukin-15 facilitates muscle regeneration through modulation of fibro/adipogenic progenitors, Cell Commun. Signal. (2018). https://doi.org/10.1186/s12964-018-0251-0.

[18] S.J. Mathew, J.M. Hansen, A.J. Merrell, M.M. Murphy, J.A. Lawson, D.A. Hutcheson, M.S. Hansen, M.

[19] A. Natarajan, D.R. Lemos, F.M.V. Rossi, Fibro/adipogenic progenitors: A double-edged sword in skeletal Angus-Hill, G. Kardon, Connective tissue fibroblasts and Tcf4 regulate myogenesis, Development. 138 (2011). https://doi.org/10.1242/dev.057463.

[20] D. Fiore, R.N. Judson, M. Low, S. Lee, E. Zhang, C. Hopkins, P. Xu, A. Lenzi, F.M.V. Rossi, D.R. Lemos, Pharmacological blockage of fibro/adipogenic progenitor expansion and suppression of regenerative fibrogenesis is associated with impaired skeletal muscle regeneration, Stem Cell Res. 17 (2016). https://doi.org/10.1016/j.scr.2016.06.007.

[21] M.N. Wosczyna, C.T. Konishi, E.E. Perez Carbajal, T.T. Wang, R.A. Walsh, Q. Gan, M.W. Wagner, T.A. Rando, Mesenchymal Stromal Cells Are Required for Regeneration and Homeostatic Maintenance of Skeletal Muscle, Cell Rep. 27 (2019). https://doi.org/10.1016/j.celrep.2019.04.074.

[22] A. Uezumi, T. Ito, D. Morikawa, N. Shimizu, T. Yoneda, M. Segawa, M. Yamaguchi, R. Ogawa, M.M. Matev, Y. Miyagoe-Suzuki, S. Takeda, K. Tsujikawa, K. Tsuchida, H. Yamamoto, S.I. Fukada, Fibrosis and adipogenesis originate from a common mesenchymal progenitor in skeletal muscle, J. Cell Sci. 124 (2011). https://doi.org/10.1242/jcs.086629.

[26] G. Blobe, W. Schiemann, H. Lodish, Role of Transforming Growth Factor $\beta$ in Human Disease, N. Engl. J. Med. 343 (2000). https://doi.org/10.1056/nejm200007203430322.

660 [27] C. Heldin, A. Moustakas, Non-Smad TGF-beta signals, J. Cell Sci. (2005).

[29] R.J. Akhurst, A. Hata, Erratum: Targeting the TGF $\beta$ signalling pathway in disease, Nat. Rev. Drug Discov. 11 (2012). https://doi.org/10.1038/nrd3878. 
[31] A.R. Gillies, R.L. Lieber, Structure and function of the skeletal muscle extracellular matrix, Muscle and Nerve. (2011). https://doi.org/10.1002/mus.22094.

[32] M. Low, C. Eisner, F. Rossi, Fibro/adipogenic progenitors (FAPs): Isolation by FACS and culture, in: Methods Mol. Biol., 2017. https://doi.org/10.1007/978-1-4939-6771-1_9.

[33] M.A. Dawson, R.K. Prinjha, A. Dittmann, G. Giotopoulos, M. Bantscheff, W.I. Chan, S.C. Robson, C.W. Chung, C. Hopf, M.M. Savitski, C. Huthmacher, E. Gudgin, D. Lugo, S. Beinke, T.D. Chapman, E.J. Roberts, P.E. Soden, K.R. Auger, O. Mirguet, K. Doehner, R. Delwel, A.K. Burnett, P. Jeffrey, G. Drewes, K. Lee, B.J.P. Huntly, T. Kouzarides, Inhibition of BET recruitment to chromatin as an effective treatment for MLL-fusion leukaemia, Nature. (2011). https://doi.org/10.1038/nature10509.

[34] M.S. Stratton, R.A. Bagchi, M.B. Felisbino, R.A. Hirsch, H.E. Smith, A.S. Riching, B.Y. Enyart, K.A. Koch, M.A. Cavasin, M. Alexanian, K. Song, J. Qi, M.E. Lemieux, D. Srivastava, M.P.Y. Lam, S.M. Haldar, C.Y. Lin, T.A. McKinsey, Dynamic Chromatin Targeting of BRD4 Stimulates Cardiac Fibroblast Activation, Circ. Res. 125 (2019). https://doi.org/10.1161/CIRCRESAHA.119.315125.

[35] E.M. Small, The Actin-MRTF-SRF gene regulatory axis and myofibroblast differentiation, J. Cardiovasc. Transl. Res. 5 (2012). https://doi.org/10.1007/s12265-012-9397-0.

[36] M. Trojanowska, Ets factors and regulation of the extracellular matrix, Oncogene. 19 (2000). https://doi.org/10.1038/sj.onc. 1204043 .

[37] E. Seki, S. De Minicis, C.H. Österreicher, J. Kluwe, Y. Osawa, D.A. Brenner, R.F. Schwabe, TLR4 enhances TGF- $\beta$ signaling and hepatic fibrosis, Nat. Med. 13 (2007). https://doi.org/10.1038/nm1663.

[38] G. Takaesu, R.M. Surabhi, K.-J. Park, J. Ninomiya-Tsuji, K. Matsumoto, R.B. Gaynor, TAK1 is Critical for

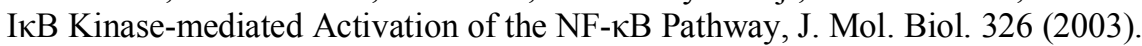
https://doi.org/10.1016/S0022-2836(02)01404-3.

[39] S. Messina, A. Bitto, M. Aguennouz, L. Minutoli, M.C. Monici, D. Altavilla, F. Squadrito, G. Vita, Nuclear factor kappa-B blockade reduces skeletal muscle degeneration and enhances muscle function in Mdx mice, Exp. Neurol. 198 (2006). https://doi.org/10.1016/j.expneurol.2005.11.021.

[40] A.L. Siegel, C. Bledsoe, J. Lavin, F. Gatti, J. Berge, G. Millman, E. Turin, W.T. Winders, J. Rutter, B. Palmeiri, C.G. Carlson, Treatment with inhibitors of the NF- $\mathrm{kB}$ pathway improves whole body tension development in the mdx mouse, Neuromuscul. Disord. (2009). https://doi.org/10.1016/j.nmd.2008.10.006.

[41] R. Maitra, M.A. Porter, S. Huang, B.P. Gilmour, Inhibition of NFאB by the natural product Withaferin A in cellular models of Cystic Fibrosis inflammation, J. Inflamm. 6 (2009). https://doi.org/10.1186/1476-9255-615.

[42] J. Wang, J. Chen, H. Jin, D. Lin, Y. Chen, X. Chen, B. Wang, S. Hu, Y. Wu, Y. Wu, Y. Zhou, N. Tian, W. Gao, X. Wang, X. Zhang, BRD4 inhibition attenuates inflammatory response in microglia and facilitates recovery after spinal cord injury in rats, J. Cell. Mol. Med. (2019). https://doi.org/10.1111/jcmm.14196.

[43] M.E. Choi, Y. Ding, S. Il Kim, TGF- $\beta$ Signaling via TAK1 Pathway: Role in Kidney Fibrosis, Semin. Nephrol. 32 (2012). https://doi.org/10.1016/j.semnephrol.2012.04.003.

[44] F. Guo, J. Hutchenreuther, D.E. Carter, A. Leask, TAK1 is required for dermal wound healing and homeostasis, J. Invest. Dermatol. 133 (2013). https://doi.org/10.1038/jid.2013.28.

[45] S. Inokuchi, T. Aoyama, K. Miura, C.H. Österreicher, Y. Kodama, K. Miyai, S. Akira, D.A. Brenner, E. Seki, Disruption of TAK1 in hepatocytes causes hepatic injury, inflammation, fibrosis, and carcinogenesis, Proc. Natl. Acad. Sci. U. S. A. 107 (2010). https://doi.org/10.1073/pnas.0909781107.

[46] D. Zhang, V. Gaussin, G.E. Taffet, N.S. Belaguli, M. Yamada, R.J. Schwartz, L.H. Michael, P.A. Overbeek, M.D. Schneider, TAK1 is activated in the myocardium after pressure overload and is sufficient to provoke heart failure in transgenic mice, Nat. Med. 6 (2000). https://doi.org/10.1038/75037.

[47] N. Biesemann, L. Mendler, S. Kostin, A. Wietelmann, T. Borchardt, T. Braun, Myostatin induces interstitial fibrosis in the heart via TAK1 and p38, Cell Tissue Res. 361 (2015). https://doi.org/10.1007/s00441-0152139-2. 
[48] Y. Ogura, S.M. Hindi, S. Sato, G. Xiong, S. Akira, A. Kumar, TAK1 modulates satellite stem cell homeostasis and skeletal muscle repair, Nat. Commun. 6 (2015). https://doi.org/10.1038/ncomms10123.

[49] S.M. Hindi, S. Sato, G. Xiong, K.R. Bohnert, A.A. Gibb, Y.S. Gallot, J.D. McMillan, B.G. Hill, S. Uchida, A. Kumar, TAK1 regulates skeletal muscle mass and mitochondrial function, JCI Insight. 3 (2018). https://doi.org/10.1172/jci.insight.98441.

[50] S. Bhatnagar, A. Kumar, D.Y. Makonchuk, H. Li, A. Kumar, Transforming growth factor- $\beta$-activated kinase 1 is an essential regulator of myogenic differentiation, J. Biol. Chem. (2010). https://doi.org/10.1074/jbc.M109.064063.

[51] K. Yamaguchi, K. Shirakabe, H. Shibuya, K. Irie, I. Oishi, N. Ueno, T. Taniguchi, E. Nishida, K. Matsumoto, Identification of a Member of the MAPKKK Family as a Potential Mediator of TGF-beta Signal Transduction, Science (80-. ). 270 (1995). https://doi.org/10.1126/science.270.5244.2008.

[52] H. Hanafusa, J. Ninomiya-Tsuji, N. Masuyama, M. Nishita, J. Fujisawa, H. Shibuya, K. Matsumoto, E. Nishida, Involvement of the p38 Mitogen-activated Protein Kinase Pathway in Transforming Growth Factor- $\beta$-induced Gene Expression, J. Biol. Chem. 274 (1999). https://doi.org/10.1074/jbc.274.38.27161.

[53] S. Il Kim, J.H. Kwak, M. Zachariah, Y. He, L. Wang, M.E. Choi, TGF- $\beta$-activated kinase 1 and TAK1binding protein 1 cooperate to mediate TGF- $\beta_{1}$-induced MKK3-p38 MAPK activation and stimulation of type I collagen, Am. J. Physiol. Physiol. 292 (2007). https://doi.org/10.1152/ajprenal.00485.2006.

[54] Q. Duan, S. McMahon, P. Anand, H. Shah, S. Thomas, H.T. Salunga, Y. Huang, R. Zhang, A. Sahadevan, M.E. Lemieux, J.D. Brown, D. Srivastava, J.E. Bradner, T.A. McKinsey, S.M. Haldar, BET bromodomain inhibition suppresses innate inflammatory and profibrotic transcriptional networks in heart failure, Sci. Transl. Med. 9 (2017). https://doi.org/10.1126/scitranslmed.aah5084.

[55] X. Tang, R. Peng, J.E. Phillips, J. Deguzman, Y. Ren, S. Apparsundaram, Q. Luo, C.M. Bauer, M.E. Fuentes, J.A. Demartino, G. Tyagi, R. Garrido, C.M. Hogaboam, C.P. Denton, A.M. Holmes, C. Kitson, C.S. Stevenson, D.C. Budd, Assessment of Brd4 inhibition in idiopathic pulmonary fibrosis lung fibroblasts and in vivo models of lung fibrosis, Am. J. Pathol. 183 (2013). https://doi.org/10.1016/j.ajpath.2013.04.020.

[56] E. Ardite, E. Perdiguero, B. Vidal, S. Gutarra, A.L. Serrano, P. Muñoz-Cánoves, PAI-1-regulated miR-21 defines a novel age-associated fibrogenic pathway in muscular dystrophy, J. Cell Biol. 196 (2012). https://doi.org/10.1083/jcb.201105013.

[57] M. van Putten, M. Hulsker, V.D. Nadarajah, S.H. van Heiningen, E. van Huizen, M. van Iterson, P. Admiraal, T. Messemaker, J.T. den Dunnen, P.A.C. 't Hoen, A. Aartsma-Rus, The effects of low levels of dystrophin on mouse muscle function and pathology, PLoS One. 7 (2012).

[58] L. Zhou, J.A. Rafael-Fortney, P. Huang, X.S. Zhao, G. Cheng, X. Zhou, H.J. Kaminski, L. Liu, R.M.

[59] K.M. Gutpel, W.T. Hrinivich, L.M. Hoffman, Skeletal muscle fibrosis in the mdx/utrn+/-mouse validates its suitability as a murine model of duchenne muscular dystrophy, PLoS One. 10 (2015). https://doi.org/10.1371/journal.pone.0117306.

[60] A.A. McDonald, S.L. Hebert, M.D. Kunz, S.J. Ralles, L.K. McLoon, Disease course in mdx:Utrophin+/mice: comparison of three mouse models of duchenne muscular dystrophy, Physiol. Rep. (2015). https://doi.org/10.14814/phy2.12391.

[61] H. Soliman, B. Paylor, R.W. Scott, D.R. Lemos, C.K. Chang, M. Arostegui, M. Low, C. Lee, D. Fiore, P. Braghetta, V. Pospichalova, C.E. Barkauskas, V. Korinek, A. Rampazzo, K. MacLeod, T.M. Underhill, F.M.V. Rossi, Pathogenic Potential of Hic1-Expressing Cardiac Stromal Progenitors, Cell Stem Cell. 26 (2020). https://doi.org/10.1016/j.stem.2019.12.008.

[62] J.J. Moslehi, M. Deininger, Tyrosine kinase inhibitor-associated cardiovascular toxicity in chronic myeloid leukemia, J. Clin. Oncol. 33 (2015). https://doi.org/10.1200/JCO.2015.62.4718.

762 [63] Z. White, C.H. Hakim, M. Theret, N.N. Yang, F. Rossi, D. Cox, G.A. Francis, V. Straub, K. Selby, C. 
Panagiotopoulos, D. Duan, P. Bernatchez, High prevalence of plasma lipid abnormalities in human and canine Duchenne and Becker muscular dystrophies depicts a new type of primary genetic dyslipidemia, J. Clin. Lipidol. (2020). https://doi.org/10.1016/j.jacl.2020.05.098.

[64] O. Contreras, M. Villarreal, E. Brandan, Nilotinib impairs skeletal myogenesis by increasing myoblast proliferation, Skelet. Muscle. 8 (2018). https://doi.org/10.1186/s13395-018-0150-5.

[65] P. Dubreuil, S. Letard, M. Ciufolini, L. Gros, M. Humbert, N. Castéran, L. Borge, B. Hajem, A. Lermet, W. Sippl, E. Voisset, M. Arock, C. Auclair, P.S. Leventhal, C.D. Mansfield, A. Moussy, O. Hermine, Masitinib (AB1010), a potent and selective tyrosine kinase inhibitor targeting KIT, PLoS One. 4 (2009). https://doi.org/10.1371/journal.pone.0007258.

[66] A. Uezumi, S. Fukada, N. Yamamoto, M. Ikemoto-Uezumi, M. Nakatani, M. Morita, A. Yamaguchi, H. Yamada, I. Nishino, Y. Hamada, K. Tsuchida, Identification and characterization of PDGFR + mesenchymal progenitors in human skeletal muscle, Cell Death Dis. 5 (2014). https://doi.org/10.1038/cddis.2014.161.

[67] H. Yokoi, M. Mukoyama, A. Sugawara, K. Mori, T. Nagae, H. Makino, T. Suganami, K. Yahata, Y. Fujinaga, I. Tanaka, K. Nakao, Role of connective tissue growth factor in fibronectin expression and tubulointerstitial fibrosis, Am. J. Physiol. - Ren. Physiol. 282 (2002). https://doi.org/10.1152/ajprenal.00122.2001.

[68] K.E. Lipson, C. Wong, Y. Teng, S. Spong, CTGF is a central mediator of tissue remodeling and fibrosis and its inhibition can reverse the process of fibrosis, Fibrogenesis Tissue Repair. 5 (2012). https://doi.org/10.1186/1755-1536-5-s1-s24.

[69] O. Contreras, D.L. Rebolledo, J.E. Oyarzún, H.C. Olguín, E. Brandan, Connective tissue cells expressing fibro/adipogenic progenitor markers increase under chronic damage: relevance in fibroblast-myofibroblast differentiation and skeletal muscle fibrosis, Cell Tissue Res. 364 (2016). https://doi.org/10.1007/s00441015-2343-0.

[70] D. Gonzalez, O. Contreras, D.L. Rebolledo, J.P. Espinoza, B. van Zundert, E. Brandan, ALS skeletal muscle shows enhanced TGF- $\beta$ signaling, fibrosis and induction of fibro/adipogenic progenitor markers, PLoS One. 12 (2017). https://doi.org/10.1371/journal.pone.0177649.

[71] C.E. Daniels, M.C. Wilkes, M. Edens, T.J. Kottom, S.J. Murphy, A.H. Limper, E.B. Leof, Imatinib mesylate inhibits the profibrogenic activity of TGF- $\beta$ and prevents bleomycin-mediated lung fibrosis, J. Clin. Invest. 114 (2004). https://doi.org/10.1172/jci19603.

[72] L.X. Wang, X. Yang, Y. Yue, T. Fan, J. Hou, G.X. Chen, M.Y. Liang, Z.K. Wu, Imatinib attenuates cardiac fibrosis by inhibiting platelet-derived growth factor receptors activation in isoproterenol induced model, PLoS One. (2017). https://doi.org/10.1371/journal.pone.0178619.

[73] C.K. Rhee, S.H. Lee, H.K. Yoon, S.C. Kim, S.Y. Lee, S.S. Kwon, Y.K. Kim, K.H. Kim, T.J. Kim, J.W. Kim, Effect of nilotinib on bleomycin-induced acute lung injury and pulmonary fibrosis in mice, Respiration. 82 (2011). https://doi.org/10.1159/000327719.

[74] M. Iyoda, T. Shibata, Y. Hirai, Y. Kuno, T. Akizawa, Nilotinib attenuates renal injury and prolongs survival in chronic kidney disease, J. Am. Soc. Nephrol. 22 (2011). https://doi.org/10.1681/ASN.2010111158.

[75] P. Piñol-Jurado, X. Suárez-Calvet, E. Fernández-Simón, E. Gallardo, N. De La Oliva, A. Martínez-Muriana, P. Gómez-Gálvez, L.M. Escudero, M. Pérez-Peiró, L. Wollin, N. De Luna, X. Navarro, I. Illa, J. DíazManera, Nintedanib decreases muscle fibrosis and improves muscle function in a murine model of dystrophinopathy, Cell Death Dis. 9 (2018). https://doi.org/10.1038/s41419-018-0792-6.

[76] F. Hong, H. Chou, M.I. Fiel, S.L. Friedman, Antifibrotic activity of sorafenib in experimental hepatic fibrosis: Refinement of inhibitory targets, dosing, and window of efficacy in vivo, Dig. Dis. Sci. (2013). https://doi.org/10.1007/s10620-012-2325-y.

[77] T.M. Fontelonga, B. Jordan, A.M. Nunes, P. Barraza-Flores, N. Bolden, R.D. Wuebbles, L.M. Griner, X. $\mathrm{Hu}, \mathrm{M}$. Ferrer, J. Marugan, N. Southall, D.J. Burkin, Sunitinib promotes myogenic regeneration and mitigates disease progression in the mdx mouse model of Duchenne muscular dystrophy, Hum. Mol. Genet. (2019). https://doi.org/10.1093/hmg/ddz044. 
[78] P. Anand, J.D. Brown, C.Y. Lin, J. Qi, R. Zhang, P.C. Artero, M.A. Alaiti, J. Bullard, K. Alazem, K.B. Margulies, T.P. Cappola, M. Lemieux, J. Plutzky, J.E. Bradner, S.M. Haldar, BET bromodomains mediate transcriptional pause release in heart failure, Cell. 154 (2013). https://doi.org/10.1016/j.cell.2013.07.013.

[79] N. Ding, N. Hah, R.T. Yu, M.H. Sherman, C. Benner, M. Leblanc, M. He, C. Liddle, M. Downes, R.M. Evans, BRD4 is a novel therapeutic target for liver fibrosis, Proc. Natl. Acad. Sci. U. S. A. 112 (2015). https://doi.org/10.1073/pnas.1522163112.

[80] C. Mozzetta, S. Consalvi, V. Saccone, M. Tierney, A. Diamantini, K.J. Mitchell, G. Marazzi, G. Borsellino, L. Battistini, D. Sassoon, A. Sacco, P.L. Puri, Fibroadipogenic progenitors mediate the ability of HDAC inhibitors to promote regeneration in dystrophic muscles of young, but not old Mdx mice, EMBO Mol. Med. 5 (2013). https://doi.org/10.1002/emmm.201202096.

[81] V. Saccone, S. Consalvi, L. Giordani, C. Mozzetta, I. Barozzi, M. Sandoná, T. Ryan, A. Rojas-Muñoz, L. Madaro, P. Fasanaro, G. Borsellino, M. De Bardi, G. Frigè, A. Termanini, X. Sun, J. Rossant, B.G. Bruneau, M. Mercola, S. Minucci, P.L. Puri, HDAC-regulated myomiRs control BAF60 variant exchange and direct the functional phenotype of fibro-adipogenic progenitors in dystrophic muscles, Genes Dev. 28 (2014). https://doi.org/10.1101/gad.234468.113.

[82] R. Müller, J. Goodrich, Sweet memories: Epigenetic control in flowering, F1000 Biol. Rep. (2011). https://doi.org/10.3410/B3-13.

[83] K. Ono, T. Ohtomo, J. Ninomiya-Tsuji, M. Tsuchiya, A dominant negative TAK1 inhibits cellular fibrotic

[84] C. Bao, Z. Yang, Q. Cai, Q. Li, H. Li, B. Shu, Incremental load training improves renal fibrosis by regulating the TGF- $\beta 1 /$ TAK1/MKK3/p38MAPK signaling pathway and inducing the activation of

[85] H.S. Cui, S.Y. Joo, Y.S. Cho, J.B. Kim, C.H. Seo, CPEB1 or CPEB4 knockdown suppresses the TAK1 and Smad signalings in THP-1 macrophage-like cells and dermal fibroblasts, Arch. Biochem. Biophys. (2020). https://doi.org/10.1016/j.abb.2020.108322.

[86] K. Singh, A. Gupta, A. Sarkar, I. Gupta, S. Rana, S. Sarkar, S. Khan, Arginyltransferase knockdown attenuates cardiac hypertrophy and fibrosis through TAK1-JNK1/2 pathway, Sci. Rep. (2020).

[87] D. Xu, S. Li, L. Wang, J. Jiang, L. Zhao, X. Huang, Z. Sun, C. Li, L. Sun, X. Li, Z. Jiang, L. Zhang, TAK1

[88] D. Xu, L. Zhao, J. Jiang, S. Li, Z. Sun, X. Huang, C. Li, T. Wang, L. Sun, X. Li, Z. Jiang, L. Zhang, A potential therapeutic effect of catalpol in Duchenne muscular dystrophy revealed by binding with TAK1, J. Cachexia. Sarcopenia Muscle. 11 (2020). https://doi.org/10.1002/jcsm.12581.

[89] D. qiu Xu, L. Zhao, S. jia Li, X. fei Huang, C. jie Li, L. xin Sun, X. hua Li, L. yong Zhang, Z. zhou Jiang, Catalpol counteracts the pathology in a mouse model of Duchenne muscular dystrophy by inhibiting the TGF- $31 /$ TAK1 signaling pathway, Acta Pharmacol. Sin. (2020). https://doi.org/10.1038/s41401-020-005151.

[90] A. Peidl, B. Perbal, A. Leask, Yin/Yang expression of CCN family members: Transforming growth factor beta 1, via ALK5/FAK/MEK, induces CCN1 and CCN2, yet suppresses CCN3, expression in human dermal fibroblasts, PLoS One. (2019). https://doi.org/10.1371/journal.pone.0218178.

[91] H. Sakurai, H. Miyoshi, J. Mizukami, T. Sugita, Phosphorylation-dependent activation of TAK1 mitogenactivated protein kinase kinase kinase by TAB1, FEBS Lett. (2000). https://doi.org/10.1016/S00145793(00)01588-X.

[92] K. Heyninck, M. Lahtela-Kakkonen, P. Van der Veken, G. Haegeman, W. Vanden Berghe, Withaferin A inhibits NF-kappaB activation by targeting cysteine 179 in IKK $\beta$, Biochem. Pharmacol. 91 (2014). https://doi.org/10.1016/j.bcp.2014.08.004. 
[93] S. Bale, P. Venkatesh, M. Sunkoju, C. Godugu, An adaptogen: Withaferin a ameliorates in vitro and in vivo pulmonary fibrosis by modulating the interplay of fibrotic, matricelluar proteins, and cytokines, Front. Pharmacol. 9 (2018). https://doi.org/10.3389/fphar.2018.00248.

[94] A.A. Challa, M. Vukmirovic, J. Blackmon, B. Stefanovic, Withaferin-A reduces type I collagen expression in vitro and inhibits development of myocardial fibrosis in vivo, PLoS One. 7 (2012).

[95] S. Dubey, H. Yoon, M.S. Cohen, P. Nagarkatti, M. Nagarkatti, D. Karan, Withaferin a associated differential regulation of inflammatory cytokines, Front. Immunol. 9 (2018). https://doi.org/10.3389/fimmu.2018.00195.

[96] E. Ferri, C. Petosa, C.E. McKenna, Bromodomains: Structure, function and pharmacology of inhibition, Biochem. Pharmacol. 106 (2016). https://doi.org/10.1016/j.bcp.2015.12.005.

[97] K. Kumar, B.T. DeCant, P.J. Grippo, R.F. Hwang, D.J. Bentrem, K. Ebine, H.G. Munshi, BET inhibitors block pancreatic stellate cell collagen I production and attenuate fibrosis in vivo, JCI Insight. 2 (2017). https://doi.org/10.1172/jci.insight.88032.

[98] B. Zhou, J. Mu, Y. Gong, C. Lu, Y. Zhao, T. He, Z. Qin, Brd4 inhibition attenuates unilateral ureteral obstruction-induced fibrosis by blocking TGF- $\beta$-mediated Nox4 expression, Redox Biol. (2017). https://doi.org/10.1016/j.redox.2016.12.031.

[99] A.C. Belkina, B.S. Nikolajczyk, G. V. Denis, BET Protein Function Is Required for Inflammation: Brd2 Genetic Disruption and BET Inhibitor JQ1 Impair Mouse Macrophage Inflammatory Responses, J. Immunol. 190 (2013). https://doi.org/10.4049/jimmunol.1202838.

[100] H.R. Gibbons, D.J. Mi, V.M. Farley, T. Esmond, M.B. Kaood, T.M. Aune, Bromodomain inhibitor JQ1 reversibly blocks IFN- $\gamma$ production, Sci. Rep. 9 (2019). https://doi.org/10.1038/s41598-019-46516-x.

[101] C. Beyer, J.H.W. Distler, Tyrosine kinase signaling in fibrotic disorders. Translation of basic research to human disease., Biochim. Biophys. Acta - Mol. Basis Dis. 1832 (2013). https://doi.org/10.1016/j.bbadis.2012.06.008.

[102] F. Grimminger, A. Günther, C. Vancheri, The role of tyrosine kinases in the pathogenesis of idiopathic pulmonary fibrosis, Eur. Respir. J. 45 (2015). https://doi.org/10.1183/09031936.00149614.

[103] E. Perdiguero, P. Sousa-Victor, V. Ruiz-Bonilla, M. Jardí, C. Caelles, A.L. Serrano, P. Muñoz-Cánoves, p38/MKP-1-regulated AKT coordinates macrophage transitions and resolution of inflammation during tissue repair, J. Cell Biol. 195 (2011). https://doi.org/10.1083/jcb.201104053.

[104] A. Reustle, M. Torzewski, Role of p38 MAPK in atherosclerosis and aortic valve sclerosis, Int. J. Mol. Sci. 19 (2018). https://doi.org/10.3390/ijms19123761.

[105] T. Borbiev, A. Birukova, F. Liu, S. Nurmukhambetova, W.T. Gerthoffer, J.G.N. Garcia, A.D. Verin, p38 MAP kinase-dependent regulation of endothelial cell permeability, Am. J. Physiol. - Lung Cell. Mol. Physiol. (2004). https://doi.org/10.1152/ajplung.00372.2003.

[106] S.A. Potthoff, S. Stamer, K. Grave, E. Königshausen, S.H. Sivritas, M. Thieme, Y. Mori, M. Woznowski, L.C. Rump, J. Stegbauer, Chronic p38 mitogen-activated protein kinase inhibition improves vascular function and remodeling in angiotensin II-dependent hypertension, JRAAS - J. Renin-AngiotensinAldosterone Syst. 17 (2016). https://doi.org/10.1177/1470320316653284.

[107] J.D. Bernet, J.D. Doles, J.K. Hall, K. Kelly Tanaka, T.A. Carter, B.B. Olwin, P38 MAPK signaling underlies a cell-autonomous loss of stem cell self-renewal in skeletal muscle of aged mice, Nat. Med. (2014). https://doi.org/10.1038/nm.3465.

[108] J. Segalés, E. Perdiguero, P. Muñoz-Cánoves, Regulation of muscle stem cell functions: A focus on the p38 MAPK signaling pathway, Front. Cell Dev. Biol. 4 (2016). https://doi.org/10.3389/fcell.2016.00091.

[109] F. Girardi, F. Le Grand, Wnt Signaling in Skeletal Muscle Development and Regeneration, in: Prog. Mol. Biol. Transl. Sci., 2018. https://doi.org/10.1016/bs.pmbts.2017.11.026. Opin. Pulm. Med. 18 (2012). https://doi.org/10.1097/MCP.0b013e3283567ff9. 
907

908

909

910

911

912

913
[111] L. Fang, A.J. Murphy, A.M. Dart, A clinical perspective of anti-fibrotic therapies for cardiovascular disease, Front. Pharmacol. 8 (2017). https://doi.org/10.3389/fphar.2017.00186.

[112] T. Desgeorges, S. Liot, S. Lyon, J. Bouvière, A. Kemmel, A. Trignol, D. Rousseau, B. Chapuis, J. Gondin, R. Mounier, B. Chazaud, G. Juban, Open-CSAM, a new tool for semi-automated analysis of myofiber crosssectional area in regenerating adult skeletal muscle, Skelet. Muscle. (2019). https://doi.org/10.1186/s13395018-0186-6. 
bioRxiv preprint doi: https://doi.org/10.1101/2021.01.20.427485; this version posted Jahuary 21, 2021. The copyright holder for this preprint (which was not certified by peer review) is the author/funde्gn All rights reserved. No reuse allowed without permission.
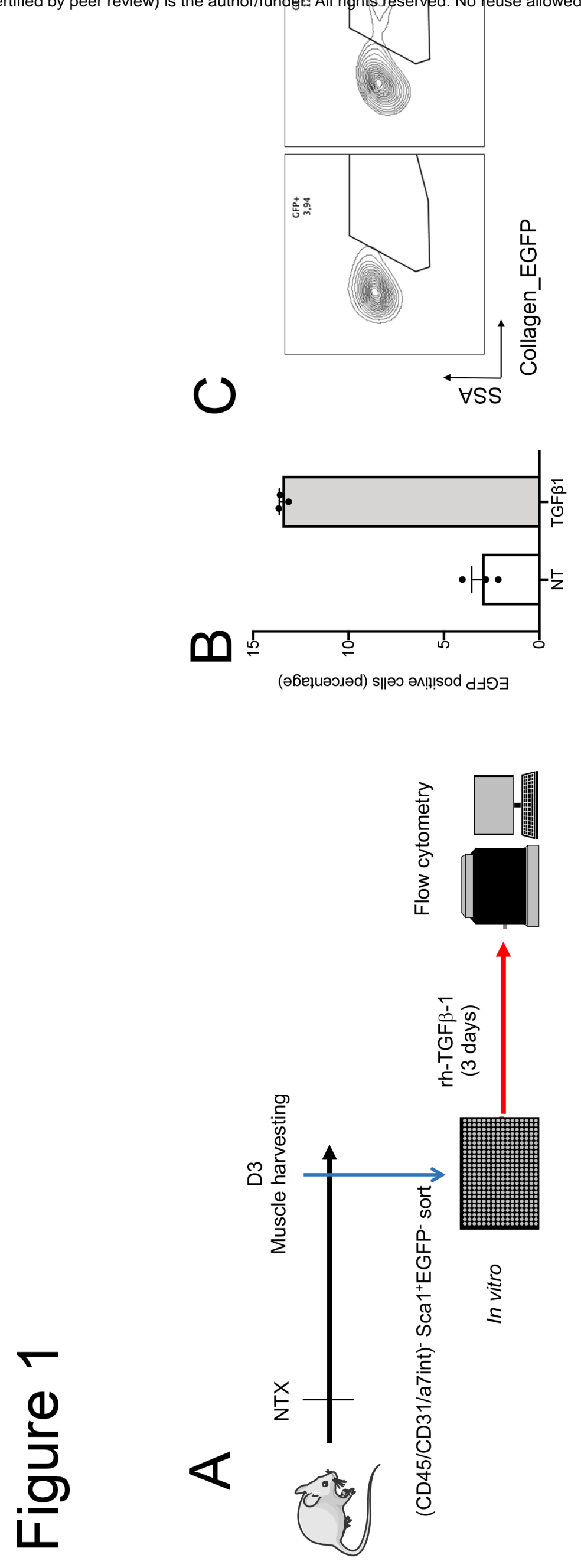
bioRxiv preprint doi: https://doi.org/10.1101/2021.01.20.427485; this version posted January 21, 2021. The copyright holder for this preprint (which was not certified by peer review) is the author/funder. All rights reserved. No reuse allowed without permission.
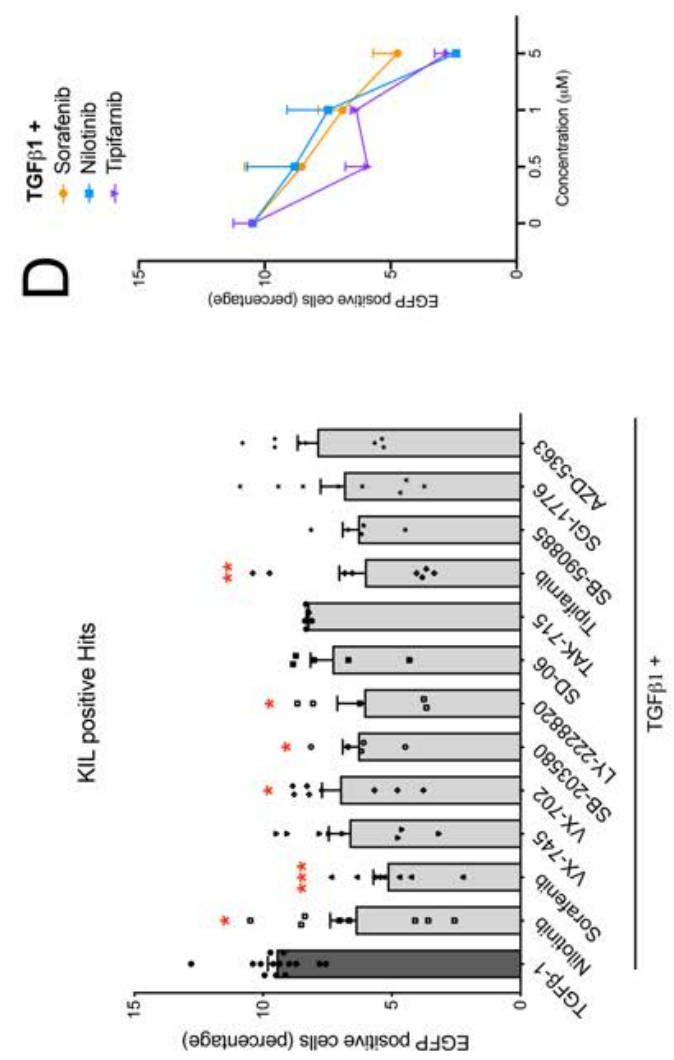

0

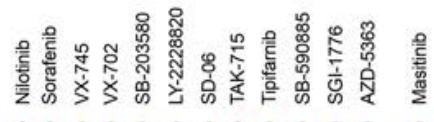

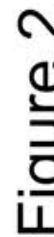

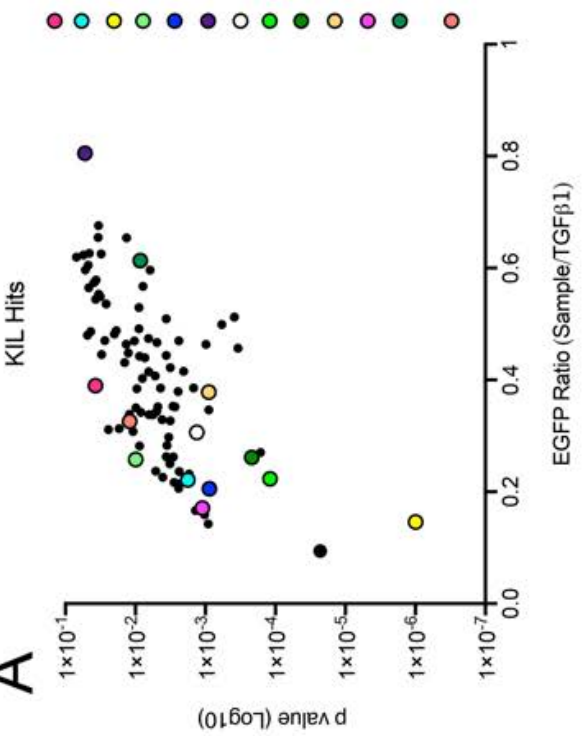

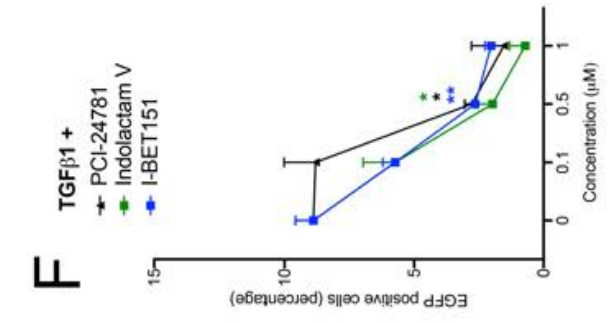
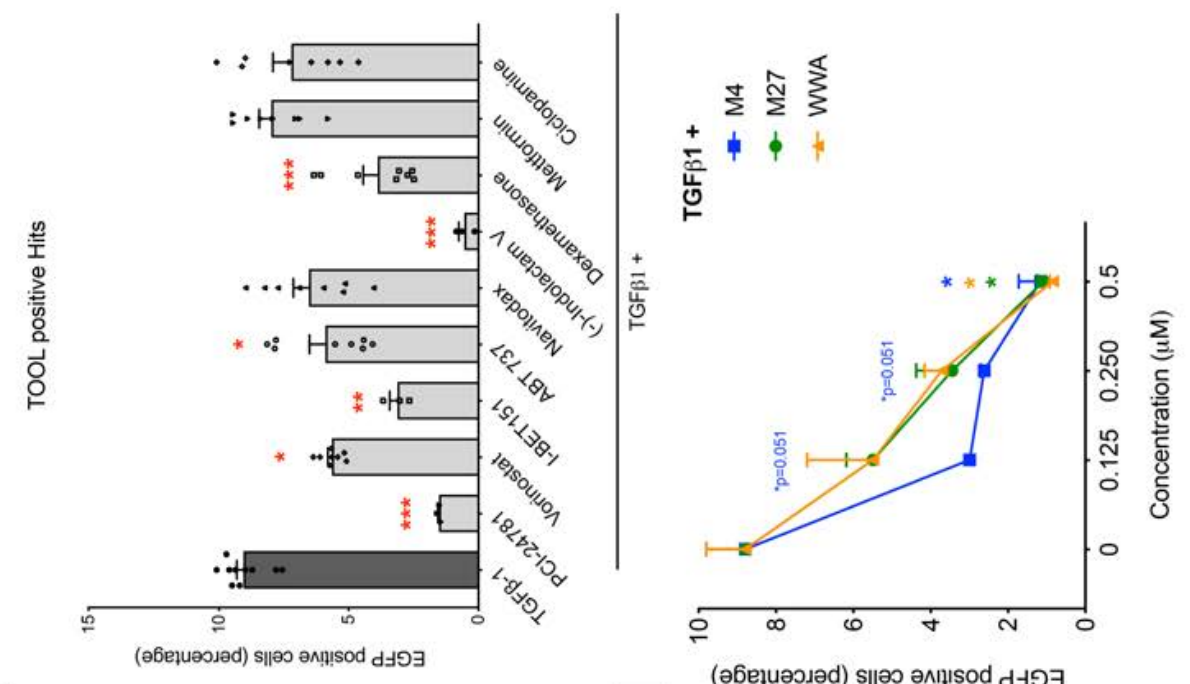

Ш

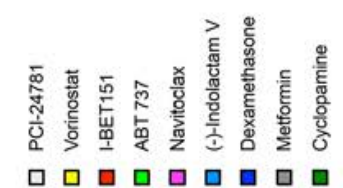

工
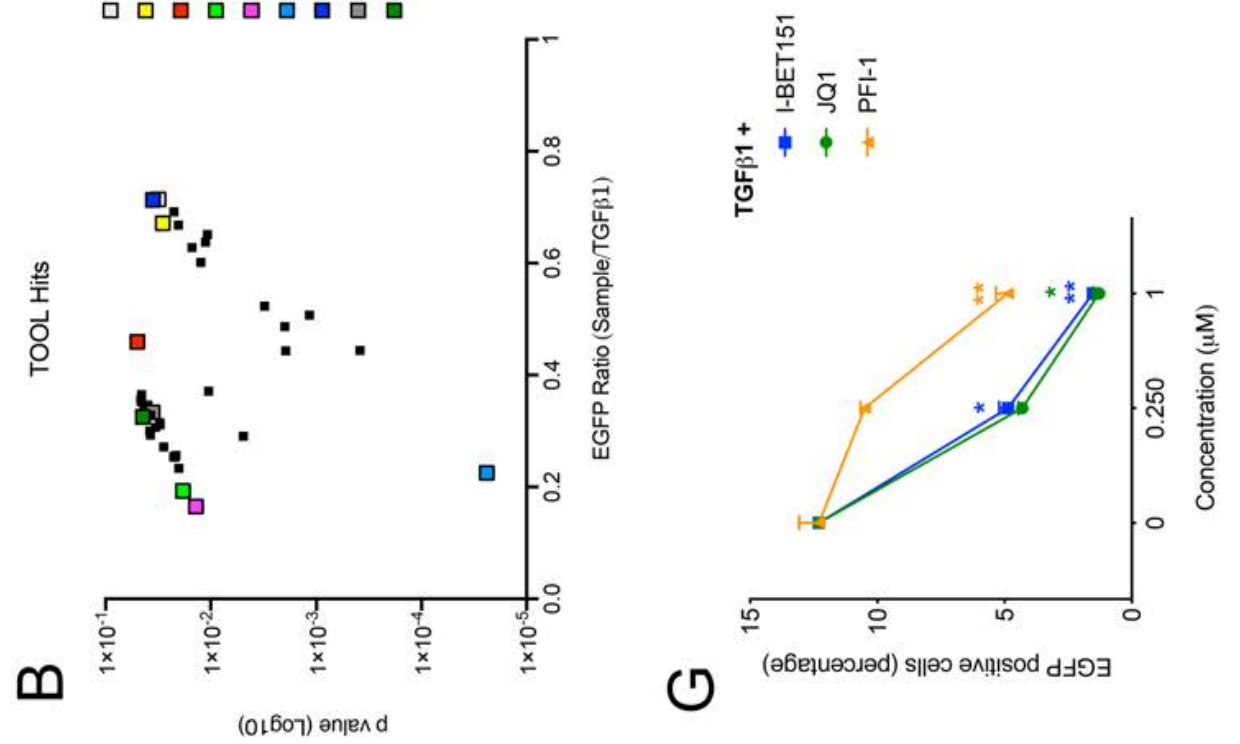

0 
bioRxiv preprint doi: https://doi.org/10.1101/2021.01.20.427485; this version posted anuarg/21, 2021. The copyright holder for this preprint (which was not certified by peer review) is the author/funder. All rights restregd. Nareuse allowed without permission.
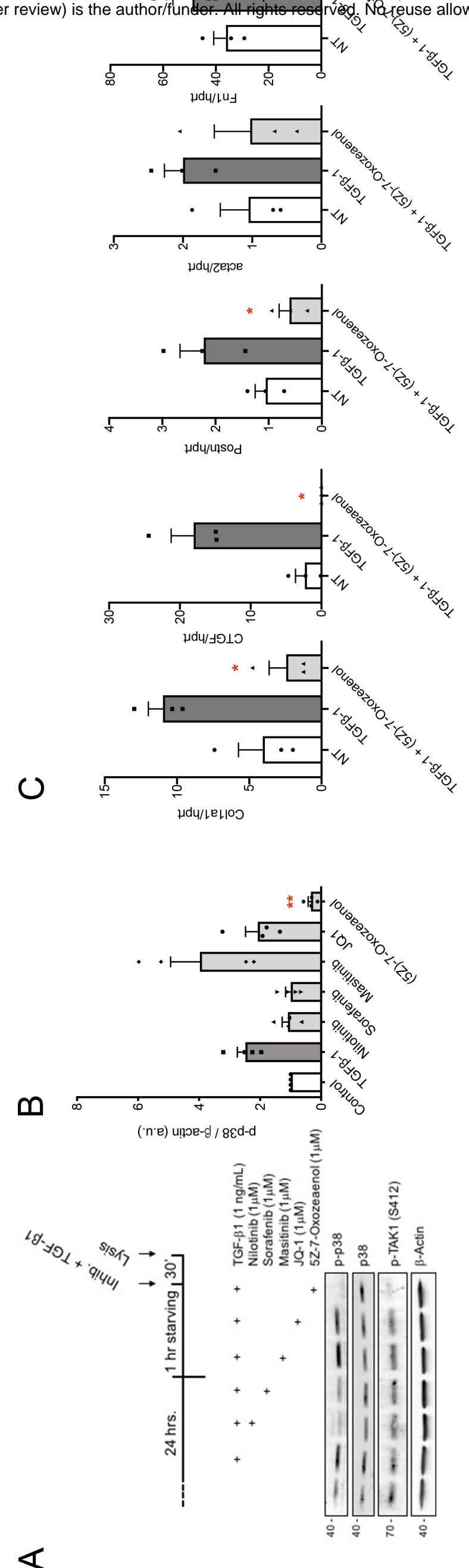


\section{Figure 4}

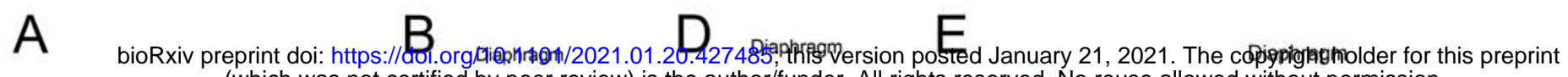
(which was not certified by peer review) is tho-author/funder. All rightşreserved.. No reuse allowed without permission.

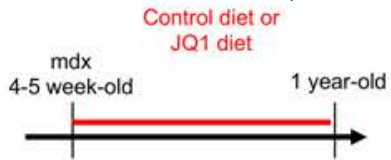

Muscle harvest

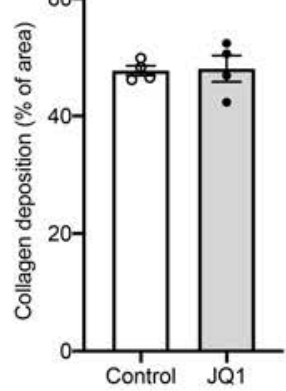

C

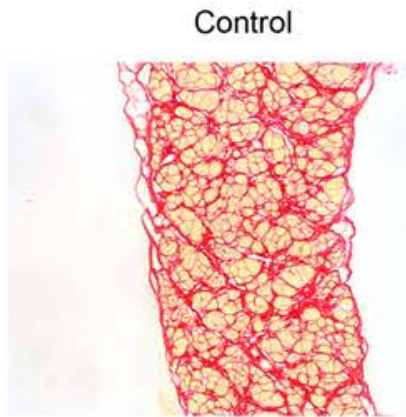

Picrosirius Red (Collagen)

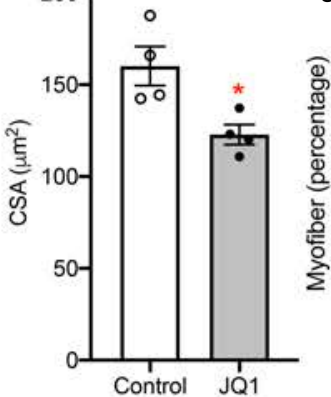

F

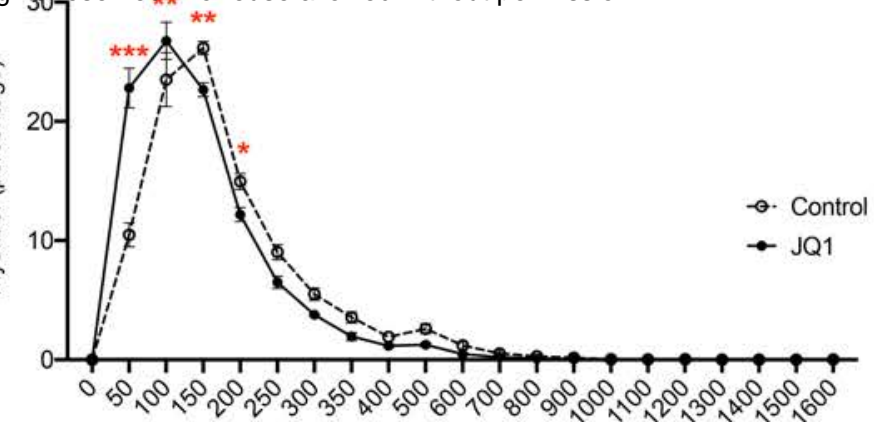

$\operatorname{CSA}\left(<\mu \mathrm{m}^{2}\right)$

Control
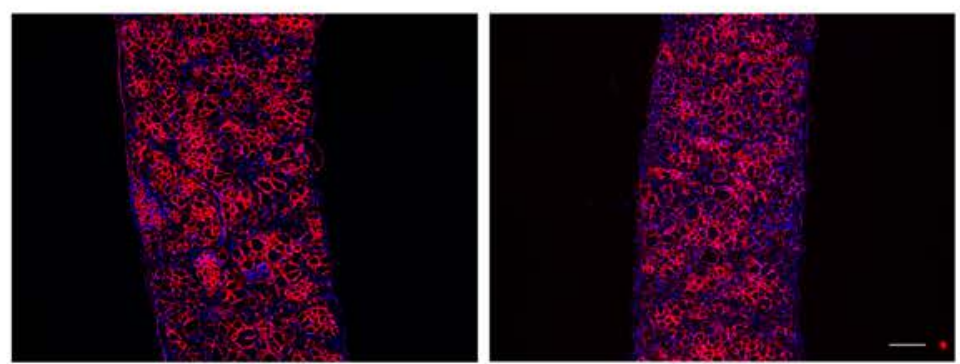

Laminin Dapi

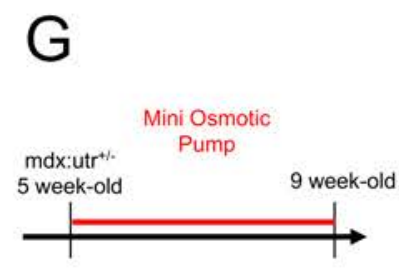

Muscle harvest

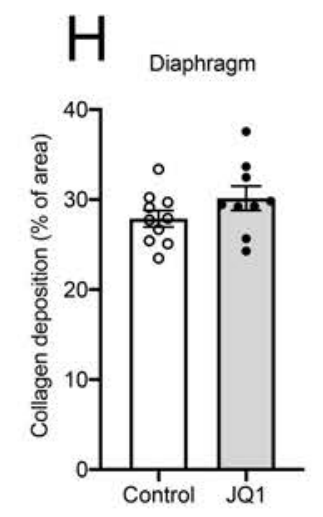

Picrosirius Red (Collagen)
JQ1
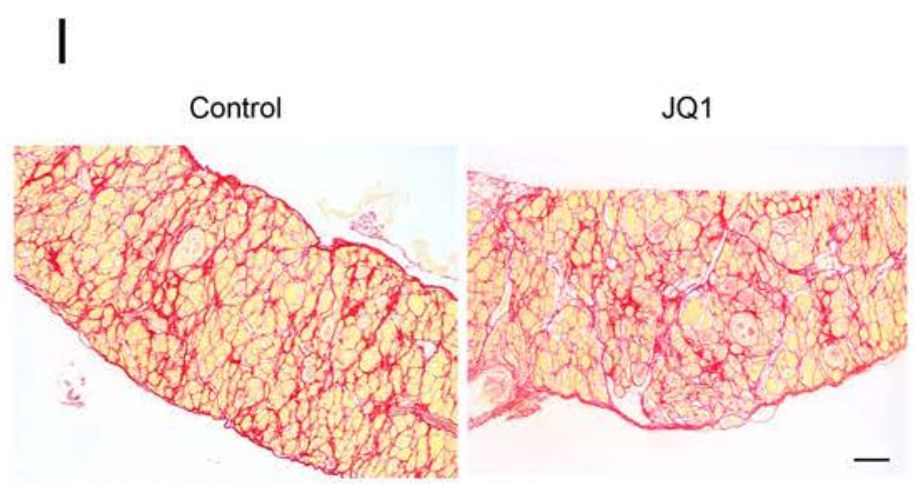
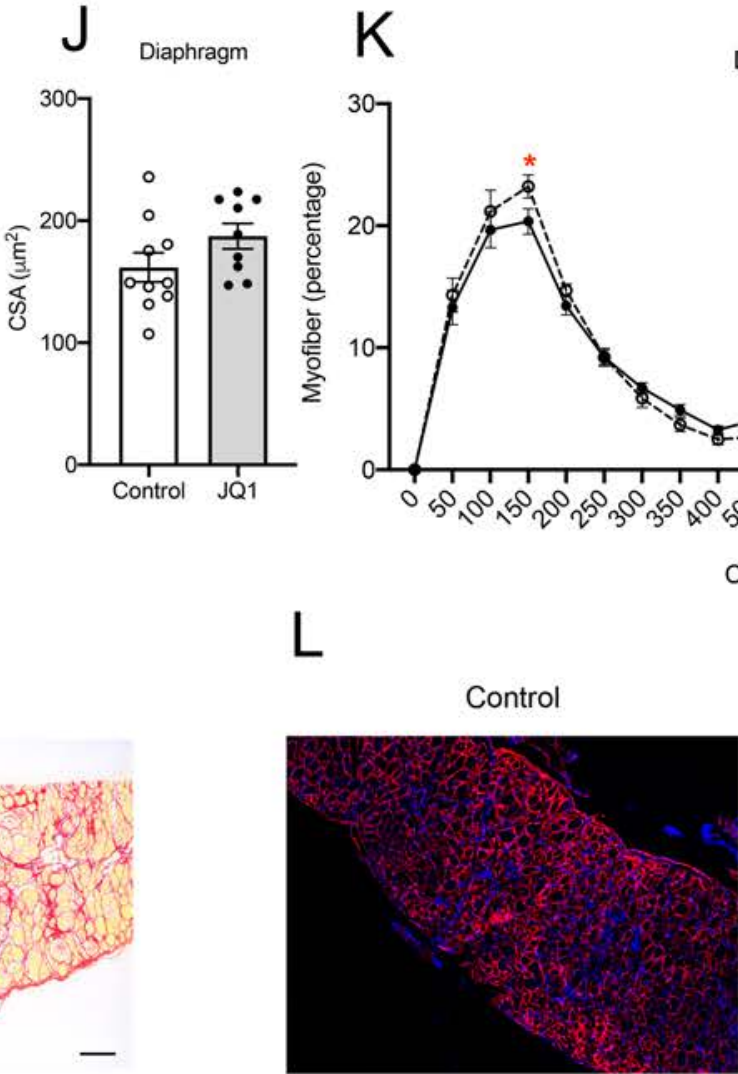

Diaphragm

๑. Control

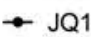

Laminin Dapi 


\section{Figure 5}

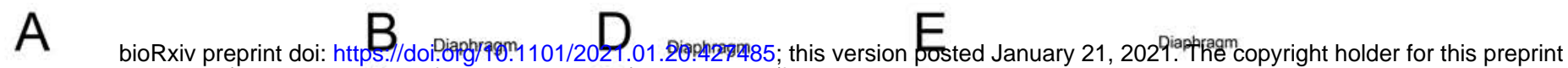

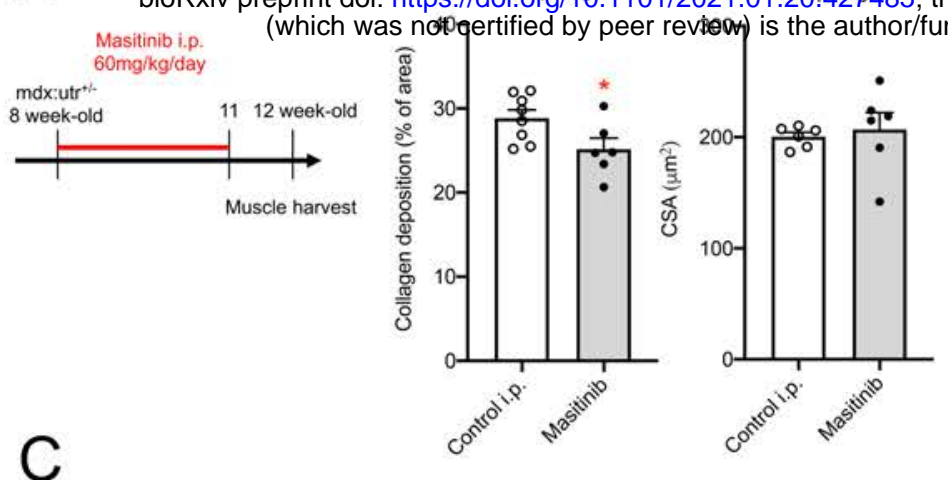

Control

Masitinib i.p.

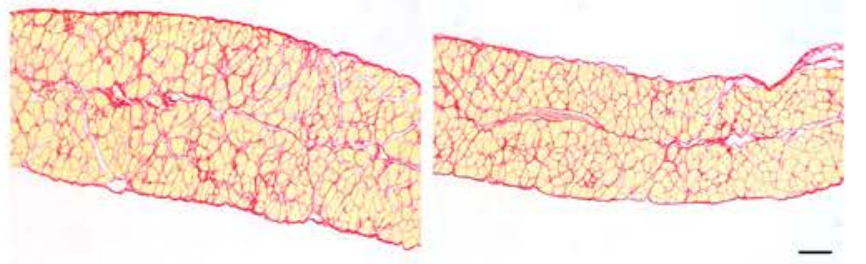

Picrosirius Red (Collagen)

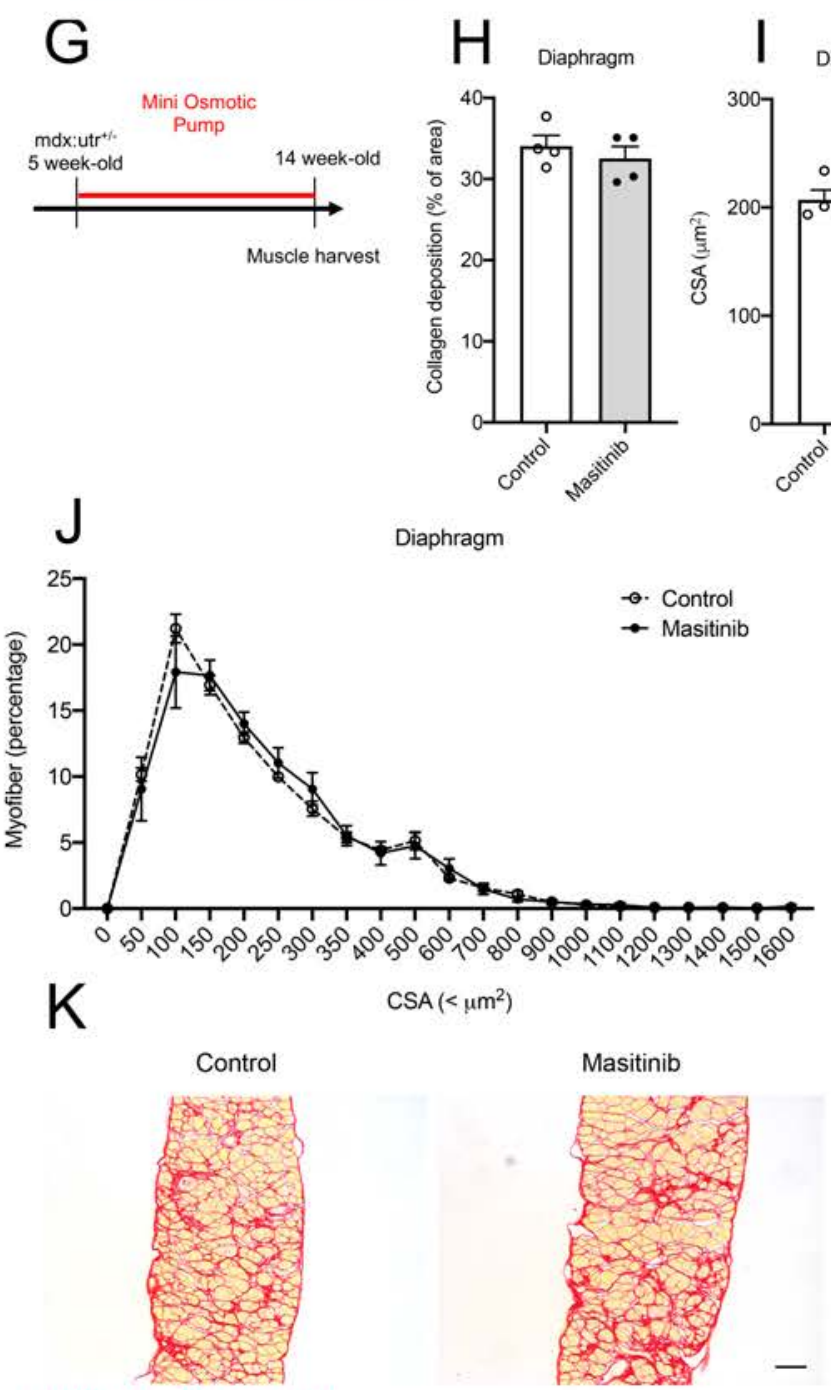
$\rightarrow$ control i.p.

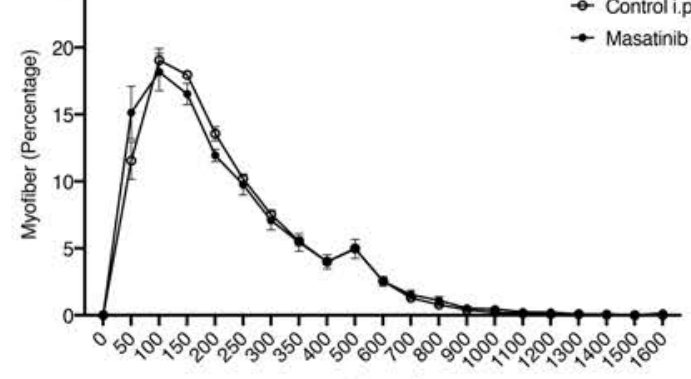

F

Control

Masitinib i.p.
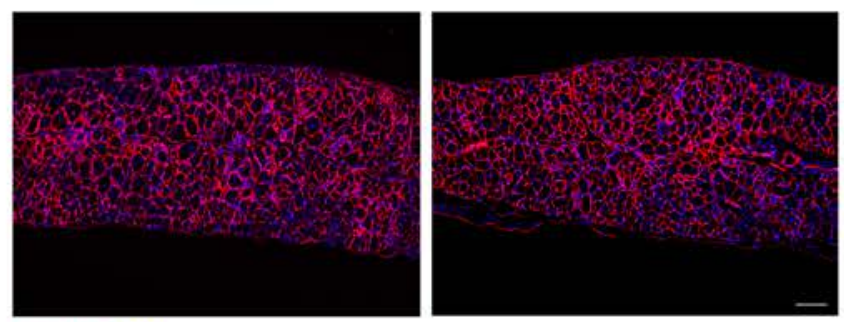

Laminin Dapi
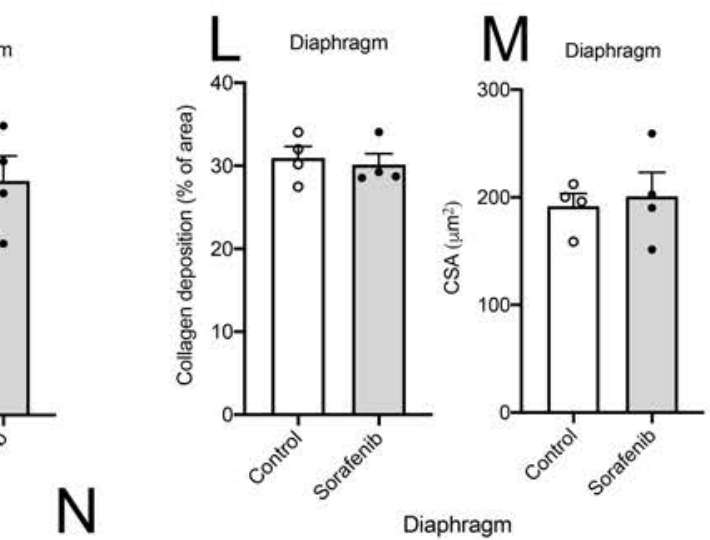

Diaphragm

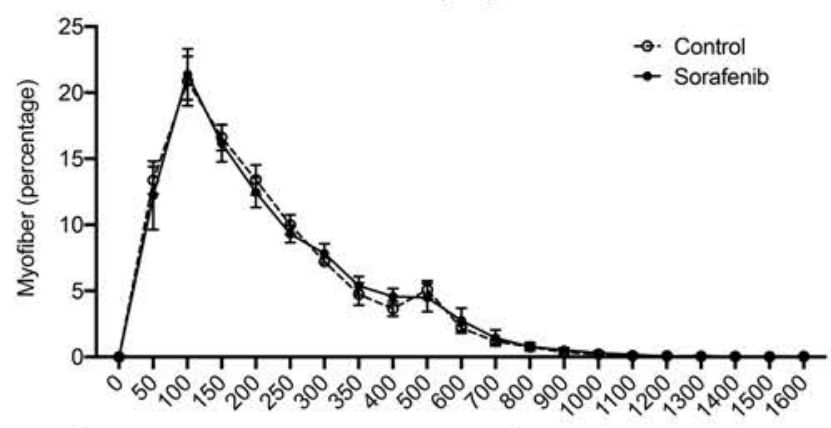

$\mathrm{O}$

$\operatorname{CSA}\left(<\mu \mathrm{m}^{2}\right)$

Picrosirius Red (Collagen)

Control

Masitinib
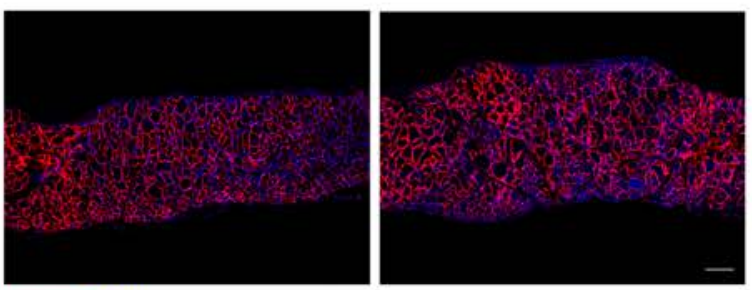

Picrosirius Red (Collacen)

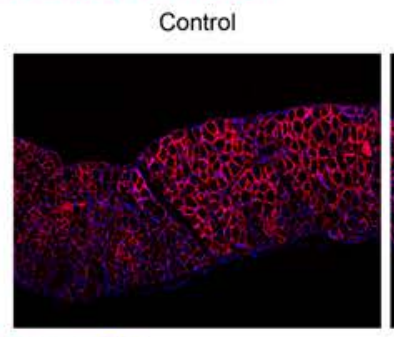

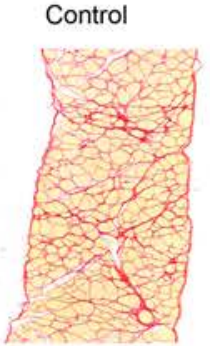

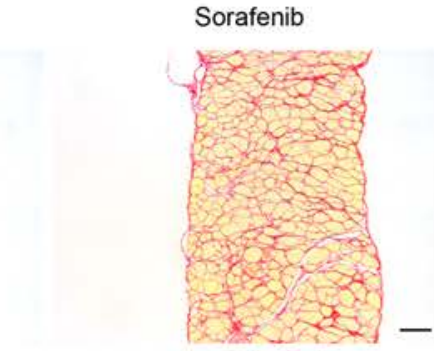

Laminin Dapi

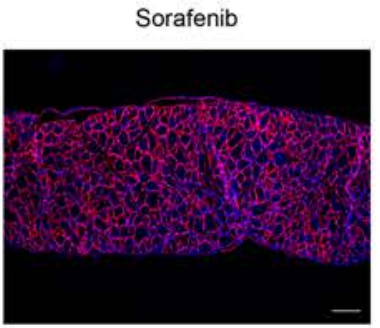




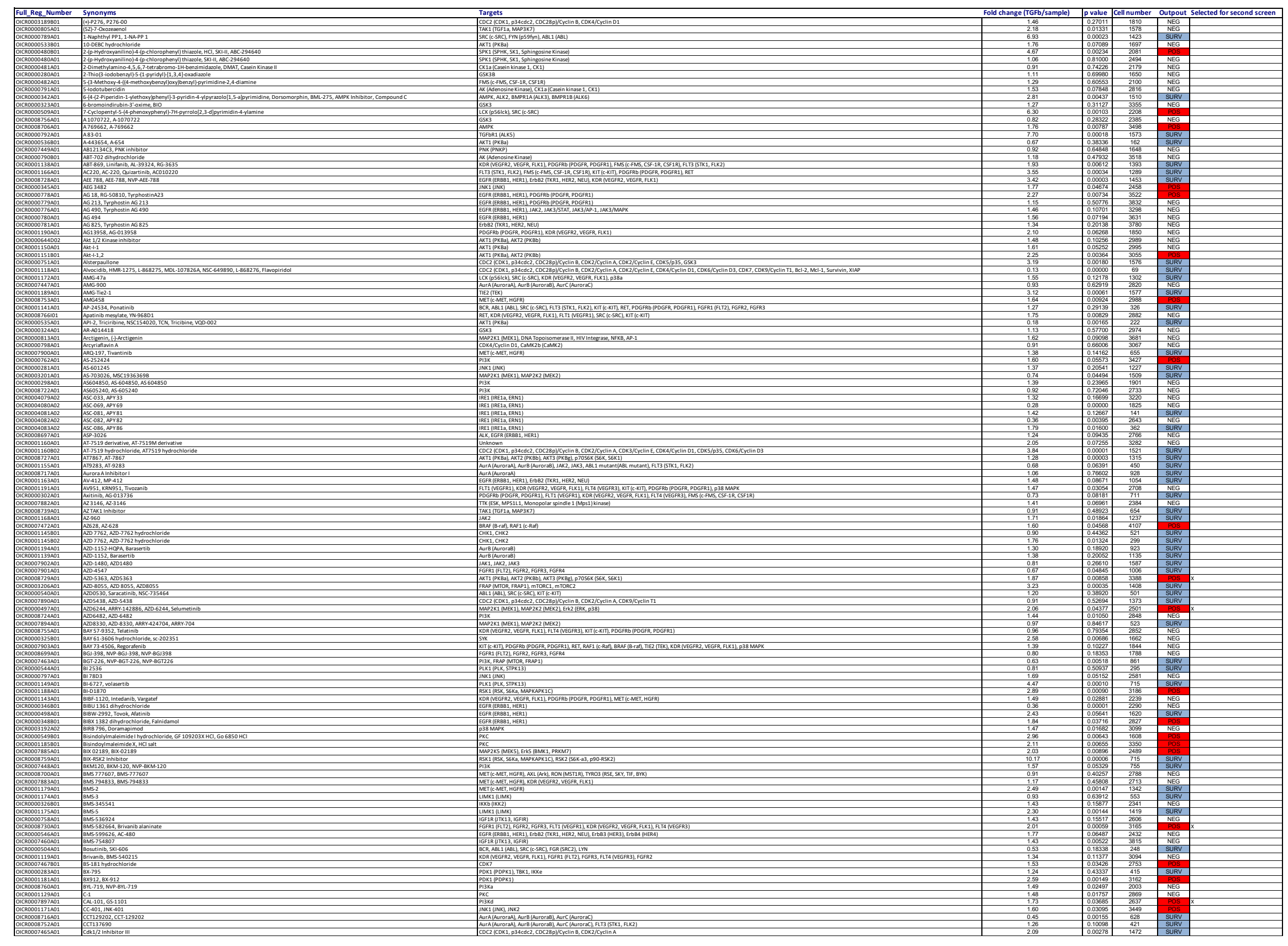




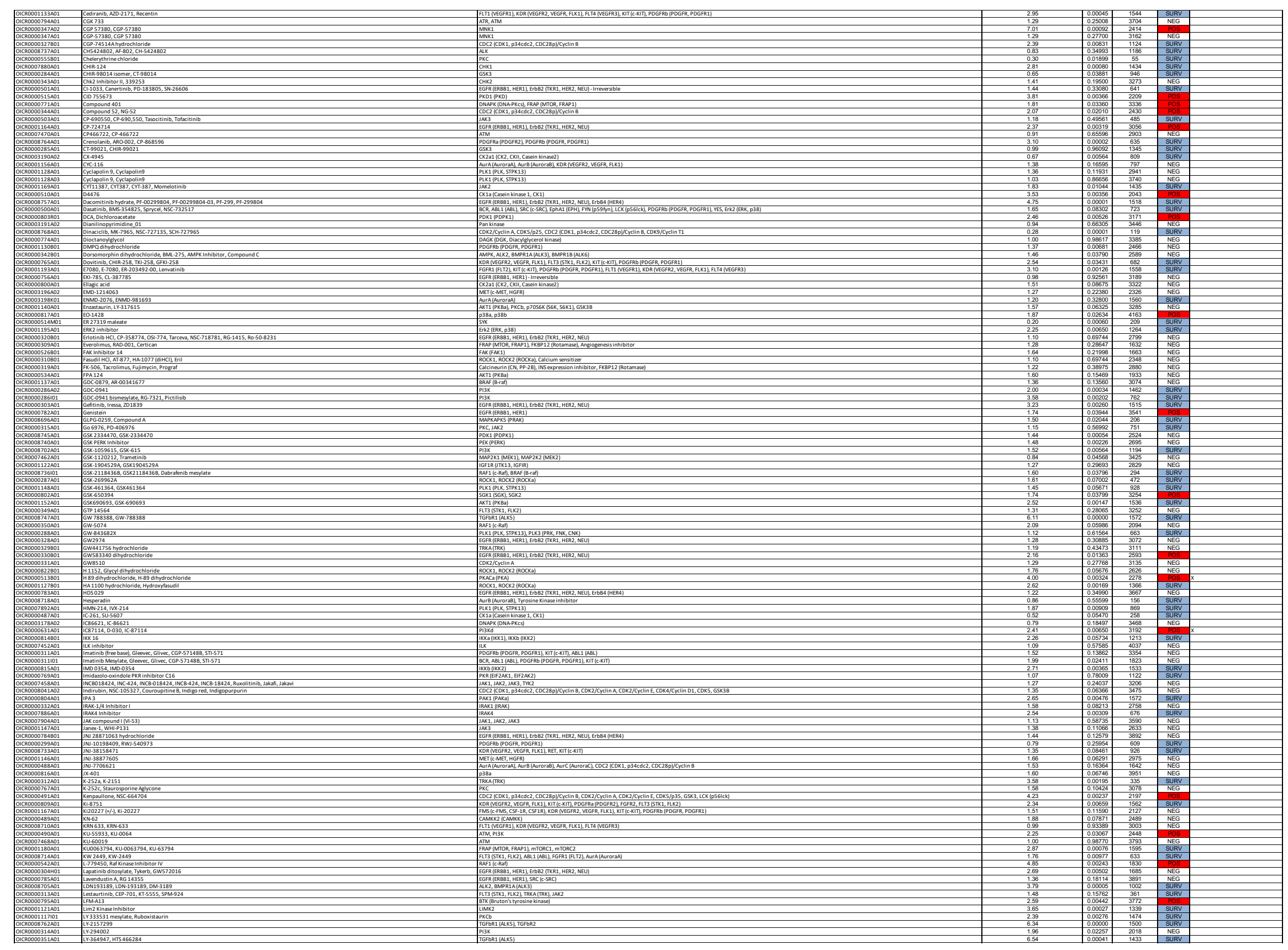




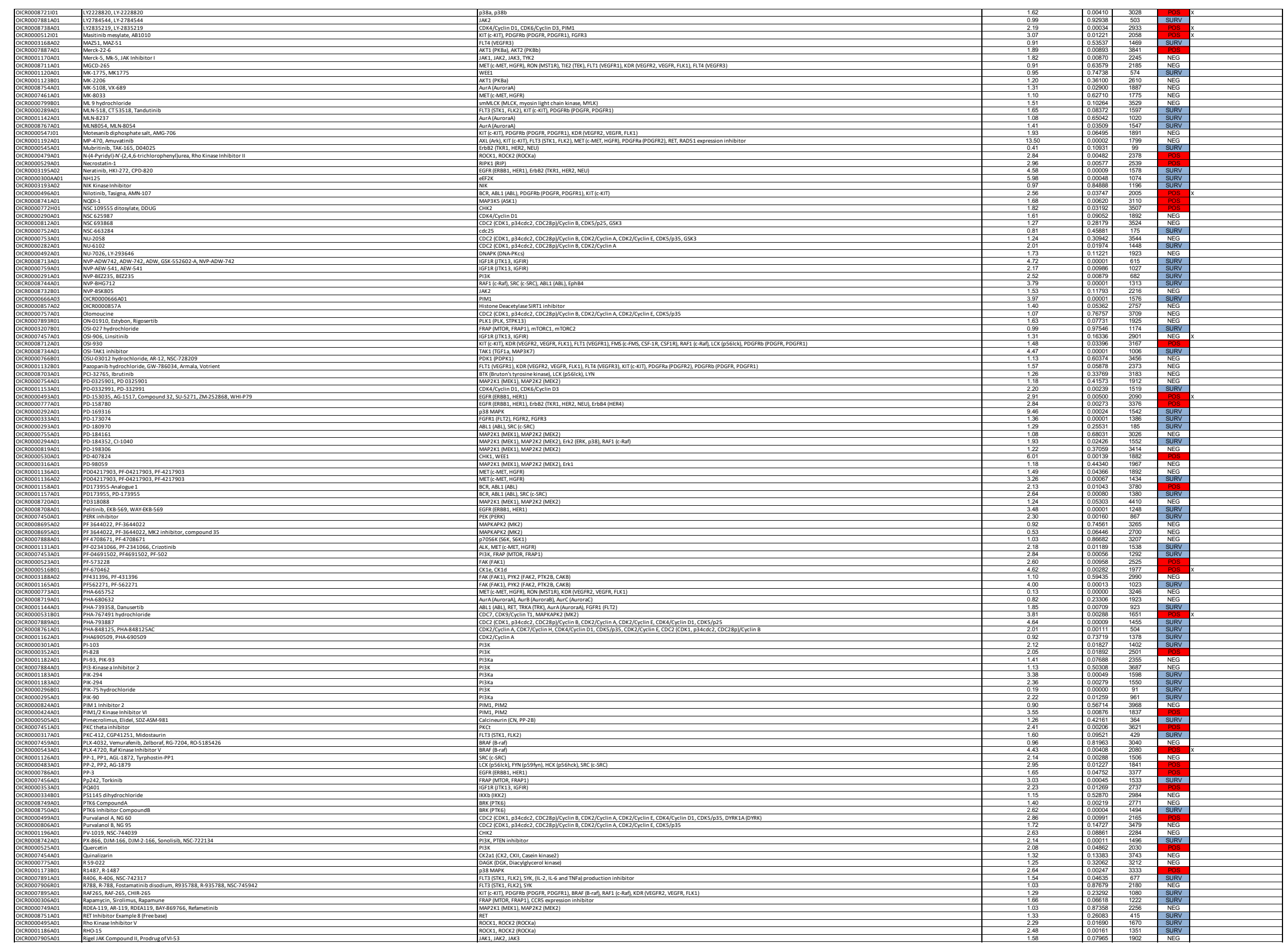




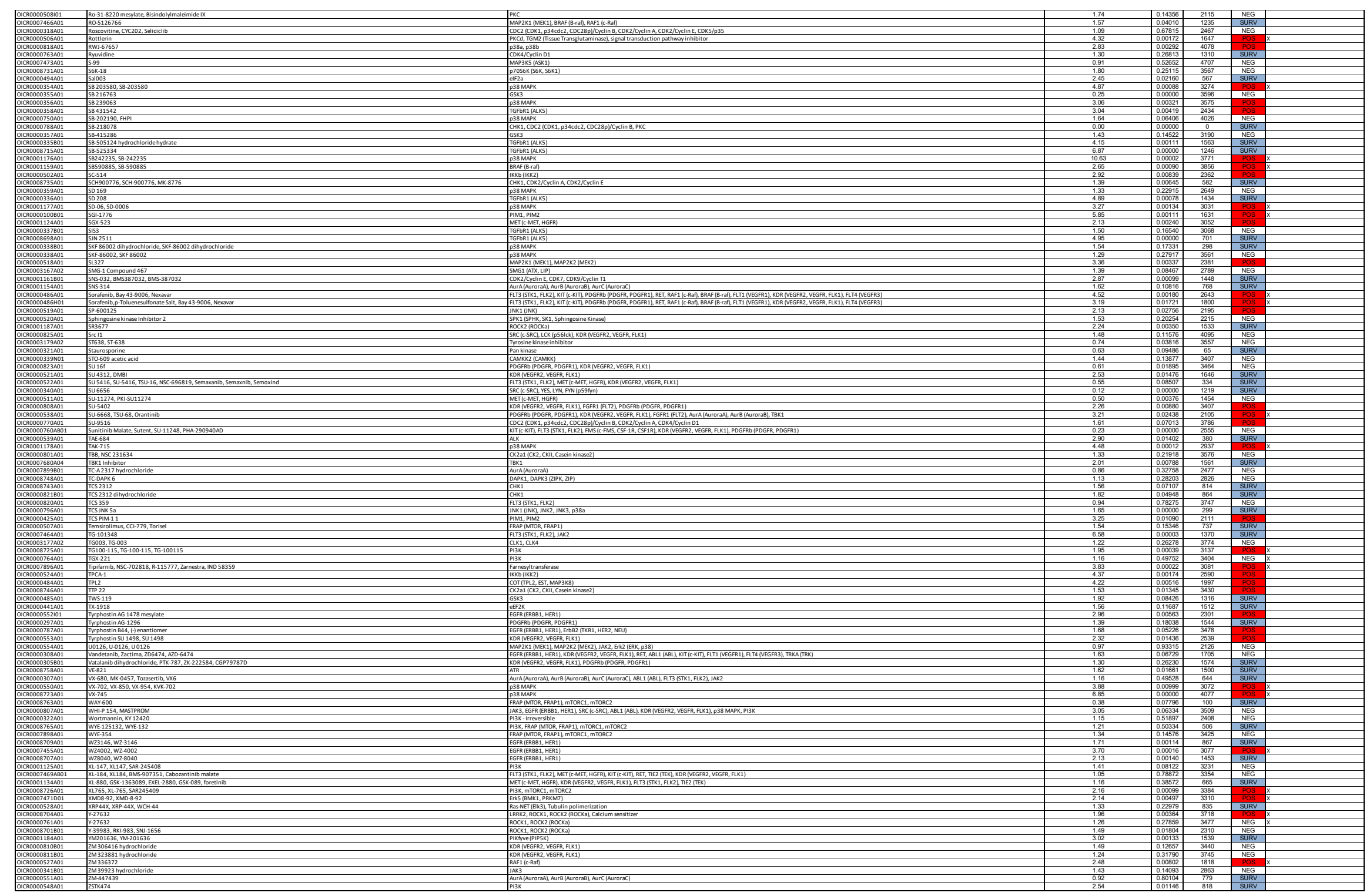



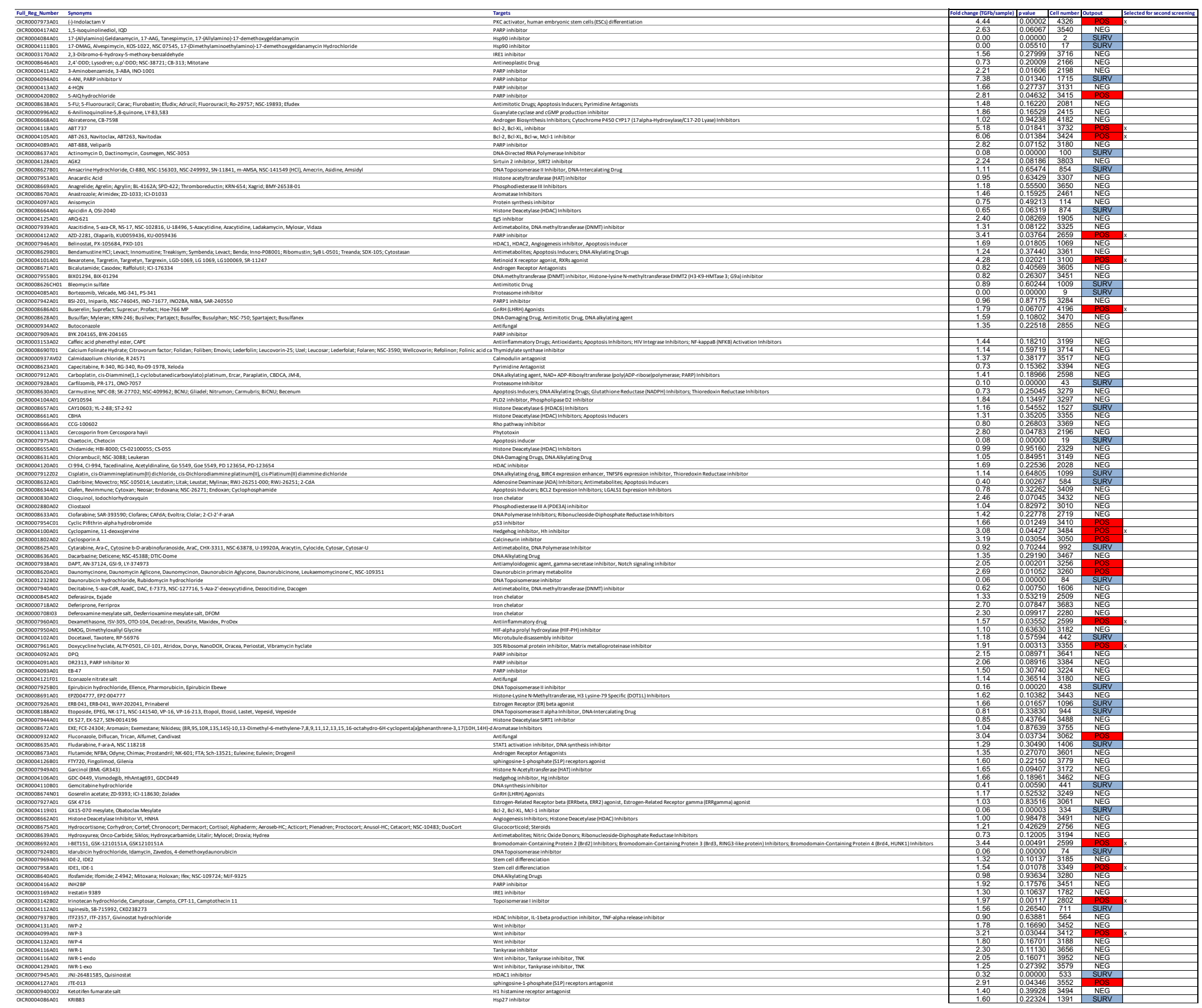


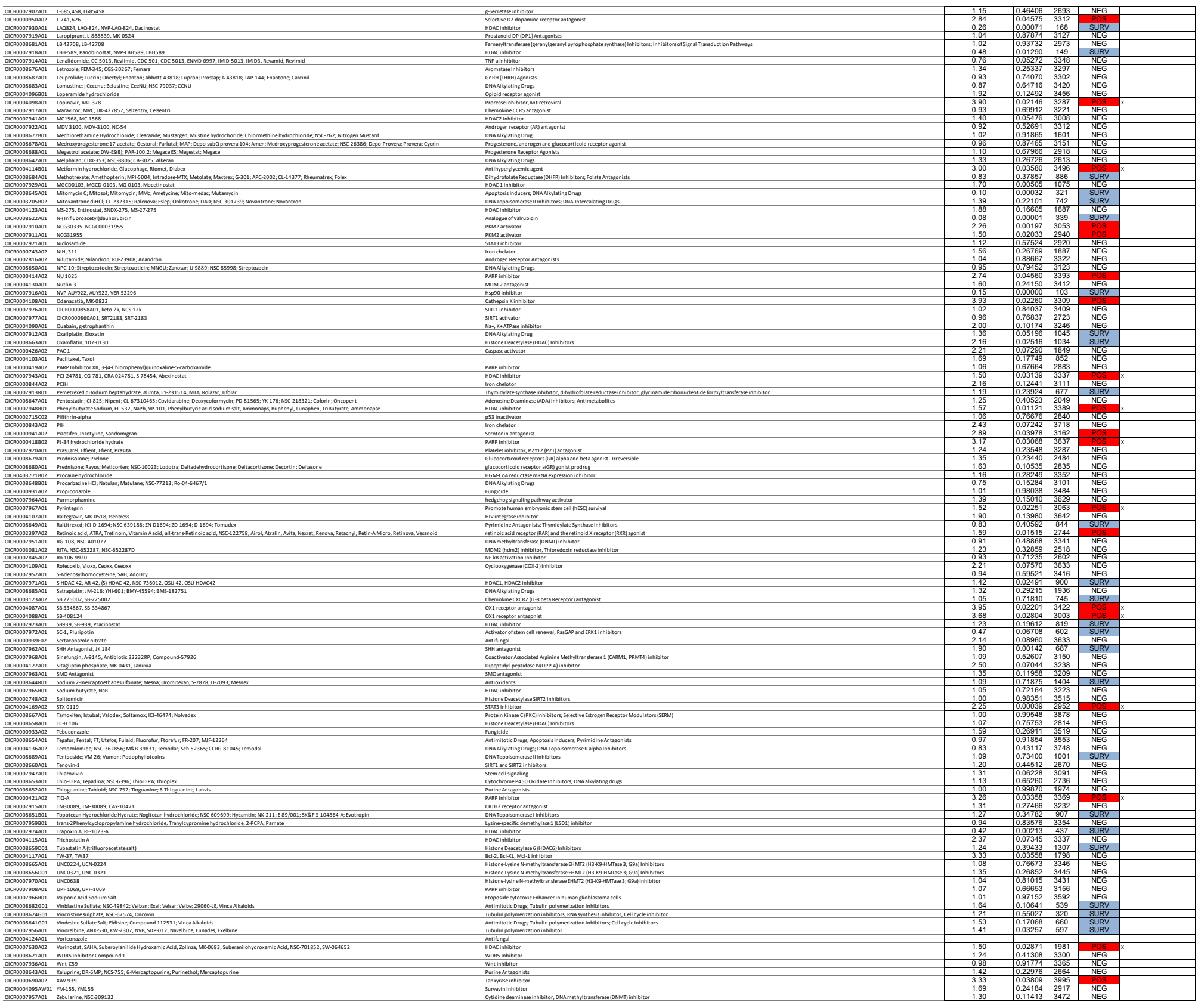




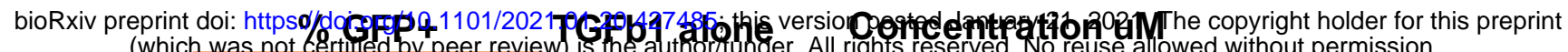

$\begin{array}{cccccc}\text { KIL COMPOUNDS } & \mathbf{0} & \mathbf{0 . 1} & \mathbf{0 . 5} & \mathbf{1} & \mathbf{5} \\ \text { SB203580 } & 9.4 & 8.09 & 6.42 & 7.93 & 3.97 \\ \text { H89 } & 9.4 & 11 & 10.3 & 6.53 & 3.21 \\ \text { PF670462 } & 9.4 & 9.67 & 6.87 & 7.16 & 3.95 \\ \text { TPCA-1 } & 9.4 & 12.3 & 10.8 & 8.49 & 3.99 \\ \text { AZD-5363 } & 9.4 & 11 & 10.3 & 6.53 & 3.21 \\ \text { RafK inh } & 9.4 & 8.9 & 8.34 & 9.41 & 3.95 \\ \text { SD-06 } & 9.4 & 9.99 & 8.15 & 7.28 & 5.55 \\ \text { TAK-715 } & 9.4 & 5.83 & 4.96 & 6.46 & 3.05 \\ \text { Wz4002 } & 9.4 & 8.09 & 7.08 & 9.53 & 1.84 \\ \text { Ly2228820 } & 9.4 & 8.2 & 6.48 & 3.51 & 3.56 \\ \text { Sorafenib } & 9.7 & 6.56 & 6.27 & 5.93 & 3.77 \\ \text { Nilotinib } & 9.7 & 7.22 & 6.94 & 5.86 & 2.02 \\ \text { Rottlerim } & 9.4 & 11.2 & 11.3 & 8.01 & 2.7 \\ \text { Masitinib } & 9.7 & 8.45 & 8.11 & 9.66 & 3.49 \\ \text { PHA-767H91 } & 9.7 & 9.79 & 10.2 & 10.9 & 4.16 \\ \text { SGI-1776 } & 9.7 & 9.05 & 8.44 & 8.37 & 2.53 \\ \text { VX-702 } & 9.7 & 7.57 & 7.17 & 5.33 & 3.7 \\ \text { SB590885 } & 9.7 & 9.01 & 7.16 & 6.06 & 1.26 \\ \text { Tipifarnib } & 9.7 & 7.12 & 6.15 & 5.02 & 2.25 \\ \text { VX745 } & 9.7 & 10.2 & 7.12 & 5.77 & 1.63 \\ \text { brivabinib } & 9.7 & 6.9 & 8.21 & 5.75 & 3.67 \\ \text { Y-27632 } & 9.4 & 8.97 & 8.74 & 8.35 & 11 \\ \text { OSI930 } & 9.4 & 9.19 & 10 & 8.29 & 7.47 \\ \text { PD153035 } & 9.7 & 6.83 & 8.14 & 8.97 & 6.55 \\ \text { Oratinib } & 9.7 & 9.96 & 9.92 & 9.75 & 8.75 \\ \text { PLX-4720 } & 9.7 & 9.01 & 8.93 & 8.09 & 9.1 \\ \text { IC87114 } & 9.7 & 8.68 & 8.46 & 5.89 & 7.75 \\ \text { TG100-115 } & 9.7 & 8.63 & 6.87 & 8.28 & 9.37 \\ \text { XL765 } & 9.7 & 9.23 & 9.38 & 5.81 & 8.03 \\ \text { LY2835219 } & 9.7 & 7.85 & 8.82 & 9.04 & 6.13\end{array}$




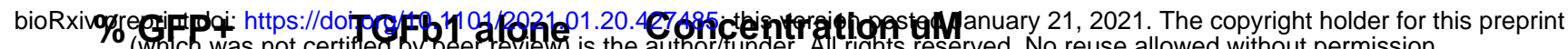

$\begin{array}{cccccc}\text { TOOL compounds } & \mathbf{0} & \mathbf{0 . 1} & \mathbf{0 . 5} & \mathbf{1} & \mathbf{5} \\ \text { Ciclopamine } & 9.4 & 10.9 & 8.03 & 7.4 & 6.15 \\ \text { Navitodax } & 9.4 & 6.96 & 6.92 & 6.03 & 5.07 \\ \text { Metformin } & 9.4 & 7.89 & 4.21 & 4.26 & 4.96 \\ \text { ABT 737 } & 9.4 & 7.89 & 4.21 & 4.26 & 4.96 \\ \text { Vorinostat } & 9.4 & 10.2 & 4.58 & 5.94 & 1.29 \\ \text { PCI-24781 } & 9.4 & 9.17 & 2.5 & 0.28 & \\ \text { Dexamethasone } & 9.4 & 5.63 & 5.39 & 2.57 & \\ \text { Indolactam V } & 9.4 & 6.94 & 3.78 & 2.59 & 1.31 \\ \text { I-BET151 } & 9.4 & 6.68 & 2.31 & 2.27 & 0.58 \\ \text { SB334867 } & 9.4 & 11.9 & 8.58 & 11 & 9.44 \\ \text { SB408124 } & 9.4 & 6.89 & 9.02 & 9.64 & 8.31 \\ \text { AZD-2281 } & 9.4 & 9.66 & 8.23 & 7.91 & 9.32 \\ \text { Lopinavir } & 9.4 & 7.89 & 9.46 & 10.5 & 7.04 \\ \text { IWP-3 } & 9.4 & 8.6 & 9.57 & 8.23 & 10.2 \\ \text { Bexarotene } & 9.4 & 8.77 & 11.1 & 11.5 & 9.65 \\ \text { Compostear } & 9.4 & 6.82 & 9.16 & 7.2 & 8.84 \\ \text { EL-532 } & 9.4 & 6.64 & 10.2 & 8.26 & 7.13 \\ \text { ID-1 } & 9.4 & 8.92 & 8.36 & 9.44 & 7.17 \\ \text { Atridox } & 9.4 & 7.56 & 8.75 & 6.79 & 5.92 \\ \text { Buserelein } & 9.4 & 9.12 & 10.5 & 9.02 & 6.64 \\ \text { STX0119 } & 9.4 & 9.4 & 10.1 & 8.72 & 8.41 \\ \text { Pyrintegrin } & 9.4 & 9.4 & 7.01 & 8.79 & \\ \text { PJ.34 } & 9.4 & 9.4 & 12.8 & 9.23 & 7.21 \\ \text { TIQ-A } & 9.4 & 9.4 & 11.8 & 9.77 & 6.88\end{array}$




\begin{tabular}{|c|c|c|c|c|c|}
\hline Compound & Target & Fold change (sample/TGFb) & $p$ value & Cell number & Outpout \\
\hline A-366 & G9a/GLP & 1.04 & 0.80466 & 4511 & NEG \\
\hline BAZ2-ICR & BAZ2A/B bromodomains & 0.78 & 0.16923 & 3555 & NEG \\
\hline C646 & p300 & 0.80 & 0.31629 & 3848 & NEG \\
\hline CL-994 & HDAC & 0.82 & 0.49564 & 2164 & NEG \\
\hline GSK-LSD1 & LSD1 & 1.30 & 0.13926 & 3965 & NEG \\
\hline GSK2801 & BAZ2A/B & 0.86 & 0.61931 & 3376 & NEG \\
\hline GSK343 & $\mathrm{EZH} 2$ & 1.17 & 0.45595 & 2400 & NEG \\
\hline GSKJ4 & JMJD3, UTX & 0.31 & 0.00128 & 895 & SURV \\
\hline I-CBP112 & CBP/p300 & 0.58 & 0.06423 & 3461 & NEG \\
\hline $10 \times 2$ & PHD2 & 0.90 & 0.54481 & 3816 & NEG \\
\hline JQ1 & pan-BRD & 0.10 & 0.00032 & 2135 & POS \\
\hline LAQ824 & HDAC & 0.45 & 0.89918 & 83 & SURV \\
\hline LLY-507 & SMYD2 & 0.48 & 0.02312 & 2305 & POS \\
\hline OF-1 & BRPR1-3 & 0.33 & 0.00780 & 318 & SURV \\
\hline OICR-9429 & WDR5 & 1.01 & 0.95879 & 3953 & NEG \\
\hline Olaparib & PARP1/2 & 0.69 & 0.05328 & 2871 & NEG \\
\hline PFI-1 & BET & 0.29 & 0.00520 & 1677 & POS \\
\hline PFI-2 & SETD7 & 0.56 & 0.01867 & 3544 & POS \\
\hline PFI-3 & SMARCA & 1.38 & 0.03138 & 4468 & NEG \\
\hline SGC-CBP30 & CREBBP/EP300 & 0.47 & 0.07700 & 3900 & NEG \\
\hline SGC0946 & DOT1L & 0.90 & 0.57856 & 3512 & NEG \\
\hline SGC707 & PRMT3 & 0.77 & 0.41633 & 3778 & NEG \\
\hline UNC0638 & G9a/GLP & 0.88 & 0.46814 & 2892 & NEG \\
\hline UNC0642 & G9a/GLP & 0.20 & 0.00105 & 3159 & POS \\
\hline UNC1215 & L3MBTL3 & 0.81 & 0.27208 & 3855 & NEG \\
\hline UNC1999 & EZH1/2 & 0.62 & 0.03198 & 2730 & POS \\
\hline
\end{tabular}

